\title{
Architectural Design Techniques of Urban Buildings in the Late 19th and Early 20th Century
}

\author{
James Dougherty ${ }^{1 *}$ \\ 1 Dover, Kohl \& Partners town planning, 1571 Sunset Drive, Coral Gables, FL 33143, USA \\ * Corresponding author, e-mail: jdougherty@doverkohl.com
}

Received: 14 December 2017, Accepted: 19 April 2018, Published online: 03 May 2018

\begin{abstract}
Urban buildings constructed in historic city centers of Europe and America in the late $19^{\text {th }}$ and early $20^{\text {th }}$ Century demonstrate a remarkable consistency of architectural excellence and harmony which can be observed from the large urban forms, down to minute details. The comprehensive system of design principles employed by architects of the time in the creation of these buildings has resulted in urban environments that achieve a very high degree of functionality as well as adaptability to the evolving needs of their modern populations. This essay explores the specific physical design techniques employed by architects of the late $19^{\text {th }}$ and early $20^{\text {th }}$ Century to achieve these remarkable results.
\end{abstract}

Keywords

historic architectural façade design techniques, urban buildings, late 19th century and early 20th century

\section{Introduction}

A widespread rebirth of walkable city building has been occurring in recent decades. Our cities, much dissipated by over-accommodation of the automobile during the last half of the $20^{\text {th }}$ Century, are once again being optimized for pedestrians and other non-automobile modes of transportation.

Many lessons for how to reconstitute our cities today have been relearned through the study of the techniques of the great European city builders of the past. Much exciting progress has been made, but one aspect that is still in much need of further study, and which would greatly benefit from the lessons of past masters, is the specific architectural façade design techniques of buildings forming dense historic European urban fabric.

Today, we can learn much from the examples of the historical centers of Europe, particularly the architecture designed during the golden era of city-building which occurred during the period of prosperity in the late $19^{\text {th }}$ and early $20^{\text {th }}$ Century. This period of rapid economic growth and blossoming of the arts (known by different names in different countries, i.e. Belle Époque in France, Gilded Age in America, Századforduló in Hungary) produced development in urban centers with a combination of remarkable ecological performance and extremely livable ambiance. This period is particularly notable for the extraordinary consistency and coherence of design principles employed throughout a diverse and eclectic array of urban architectural design languages (including various flavors of Historical Revival, Victorianism, Secessionism, and Art Nouveau among others).

Sadly, these design principles and methods of historic European urban buildings fell into disuse and atrophy during the postwar decades-long era of automobile-centric development. Fortunately, though, among the generations of architects during the late $19^{\text {th }}$ and early $20^{\text {th }}$ Century, there were many who industriously engaged in writing down their methods for the benefit of future generations. While respecting beneficial architectural advances that have been made in the interim, we can learn much from their excellent writings to help reconstitute the body of knowledge and skills needed to once again move forward today with expressive works utilizing the living language of traditional European urban architecture.

2 Cities of the Late $19^{\text {th }}$ and Early $20^{\text {th }}$ Century, a model European cities of the late $19^{\text {th }}$ and early $20^{\text {th }}$ Century physically function particularly well for their inhabitants. They utilize their land area very efficiently, and the finegrained mix of uses combined with intense residential 


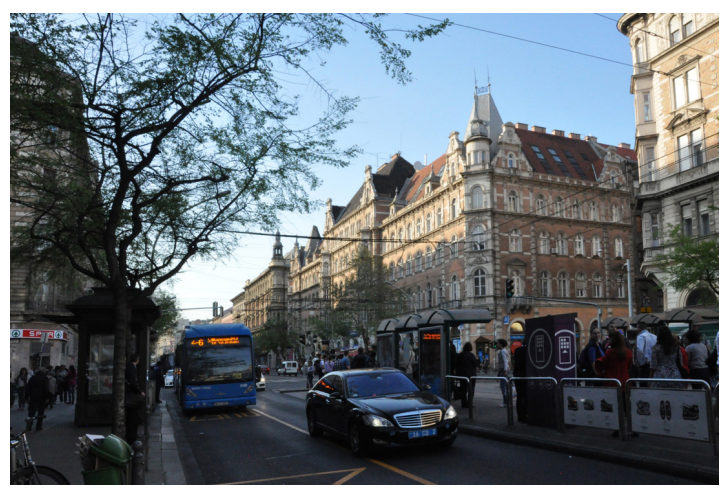

Fig. 1 Constructed in the $19^{\text {th }}$ century, Budapest's Teréz körút has elegantly adapted to fulfill modern functional requirements.

Photo: James Dougherty

densities in a low-rise format are highly conducive to walking and make environmentally beneficial things like public transportation systems very workable. This marvelous functionality is also paired with very attractive surface treatment of the buildings that help make such intense development not just palatable, but romantic and desirable.

\section{Rediscovering lost classic architectural design instructional texts}

So, if city after city in the late $19^{\text {th }}$ and early $20^{\text {th }}$ Century was constructed with building after building, and virtually every single one - thousands upon thousands of buildings altogether - all coexisted to create such beautiful and harmonious places, there must have been a common design language that was spoken by all the designers. And this language must have been written down in texts since the Academies of architecture were so formalized during this period.

Unfortunately, almost no texts from this period are studied today in the curricula of the schools of architecture around the world. However, as more and more libraries are scanning their resources and making them available online, it is becoming possible to rediscover texts that were lost during the half-century-long post-war period of auto-oriented development.

Some of these texts were written by the esteemed professors of the École Nationale Superieure des Beaux-Arts in Paris. These include Julien Guadet's seminal Éléments et Théorie de l'Architecture, which is, unfortunately, today still only available in French. Georges Gromort also wrote a number of wonderful texts, including his Elements of Classical Architecture, which has been translated into English and has been recently reprinted.

Fortunately, during the early $20^{\text {th }}$ Century, for several decades in the United States there existed a Beaux-Arts

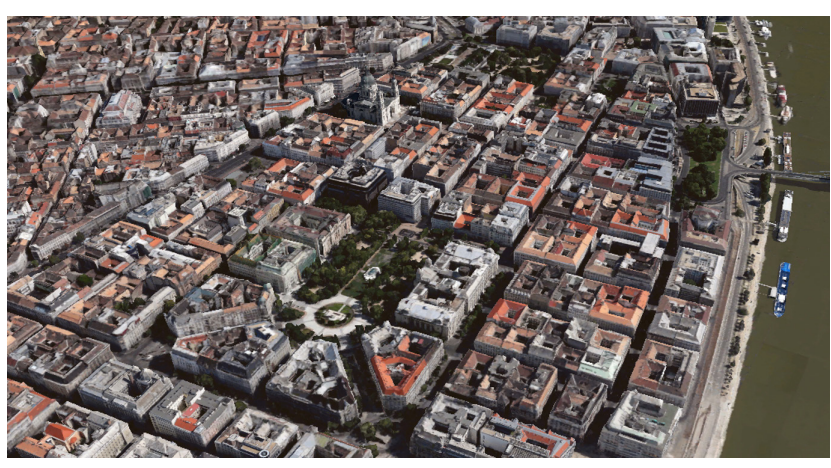

Fig. 2 The highly livable $19^{\text {th }}$ century fabric of Budapest's central Lipótváros neighborhood. Photo: Google 2017

Institute of Design. Various instructors produced numerous texts in English instructing classic Beaux-Arts methods and principles of architectural design. These clear and concise texts make a resurrection of their very useful methods possible today.

All these books consistently advocate architectural design that achieves the characteristics of stability, legibility and harmony (Robinson, 1908:pp.8-18; Curtis, 1923:pp.1-5). Perhaps this is a result of the late $19^{\text {th }}$ and early $20^{\text {th }}$ Century being a period of prosperity not long separated from periods of upheaval and strife. Architects felt an impulse to create particularly human and nurturing environments through their works.

For those interested in continuing to learn directly from the compelling voices of the architects of the late $19^{\text {th }}$ and early $20^{\text {th }}$ Century, below are a selection of recommended original texts. These have all been digitized and can be found today in various collections online:

Foundational texts from the École Nationale Supérieure des Beaux-Arts - Paris:

- Eléments et Théorie de l'Architecture (4 volumes) by Julien Guadet, 1906

- Elements of Classical Architecture by Georges Gromort, 1927.

Texts about architectural composition:

- Architectural Composition by John Beverley Robinson, 1908

- Architectural Composition by Nathaniel Cortland Curtis, 1923

- The Essentials of Composition as Applied to Art by John Vredenburgh Van Pelt, 1913. 
Texts about architectural design method:

- Architectural Rendering in Wash by H. Van Buren Magonigle, 1922

- Indication in Architectural Design by David Jacob Varon, 1916

- The American Vignola, A Guide to the Making of Classical Architecture by W. R. Ware, 1906

- The Study of Architectural Design by John Harbeson, 1927.

History / reference texts:

- Les Concours Publics d'Architecture (15 volumes), 1895

- Materials and Documents of Architecture and Sculpture (10 volumes) by A. Raguenet, 1915

- The Foundations of Classic Architecture by Herbert Langford Warren, 1919.

\section{4 "Architectural Composition" by John Beverley Robinson}

One of the very best of these fascinating texts is Architectural Composition by John Beverley Robinson. The subtitle of this book is quite remarkable: "An attempt to order and phrase ideas, which hitherto have been only felt by the instinctive taste of designers". In his book, Robinson is focusing on recording for posterity the design language that had previously been passed from architect to architect in the atelier system in a largely oral tradition.

The following is a summary of Robinson's key findings. I hope by delving into the detail of Robinson's book I can communicate the value of examining other classic architectural design instructional texts of the late $19^{\text {th }}$ and early $20^{\text {th }}$ Century.
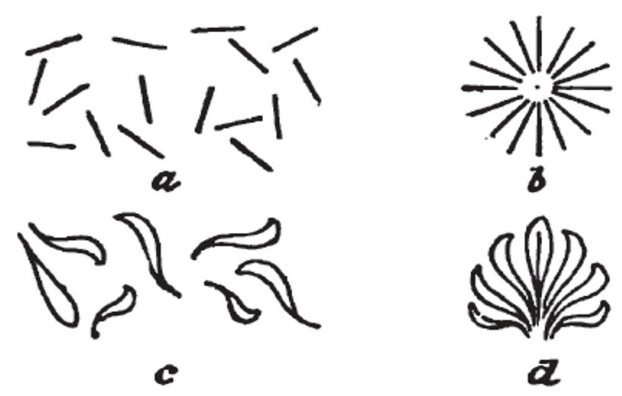

\section{r10101010101010101016}

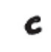

Fig. 3 The grouping of multiple elements to produce a sense of unity. From Architectural Composition by J. B. Robinson, 1908

\section{Unity}

Robinson begins with a discussion of what he feels is the principal goal of both the design of individual buildings and the urban spaces they form: the expression of unity.

Robinson states that "in all works of fine art there is one fundamental quality, which, from antiquity, has been recognized as essential; this quality is unity." Great architecture provides a sense of clarity, harmony and legibility. Architecture that embodies these traits, and which eliminates discord, is said to possess unity (Robinson, 1908:p.19).

Robinson explains, "one of the chief sources of unity in the arts of design, including architecture, lies in the placement and arrangement of parts, by which objects otherwise unrelated are so placed that the mind loses sight of them as separate objects, and notes only the combination as a single whole." In the same way that a friend's face is more than just an assortment of eyes, nose, mouth and ears, a collection of columns and moldings, if arranged properly, becomes a portico. The whole is greater than the sum of its parts (Robinson, 1908:p.19).

Robinson illustrates, "a number of lines taken at random and laid in no particular order, cannot impress the mind otherwise than as a multitude of objects. Fig. 3 a) Placed thus (b), radiating from the center, the mind regards the combination as a single star or flower and forgets to enumerate its parts at all. Such forms as these (c) remain isolated individuals until they are combined in a honeysuckle (d). Another source of unity is the intrinsic power of certain forms when properly placed. Thus, in an enriched molding, the forms of the enrichment acquire unity merely by their arrangement in a straight line (e); just as in (b), unity was created by arrangement in a circle. The addition of horizontal straight lines on

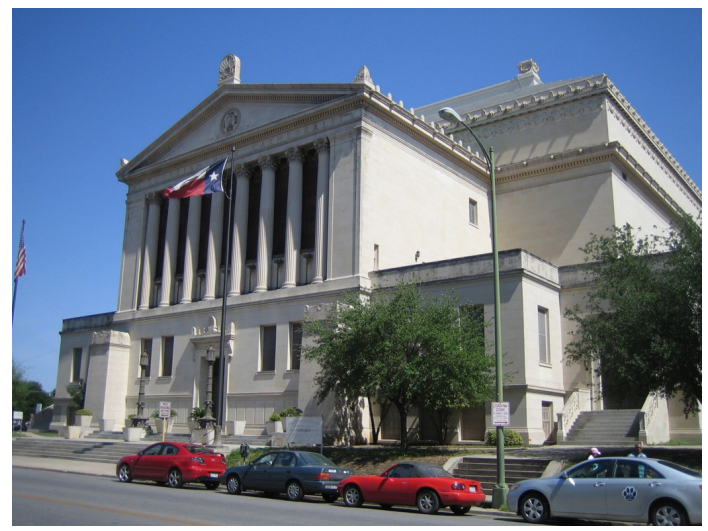

Fig. 4 The portico - a classic example of the arrangement of diverse elements to achieve a high degree of unity can be seen in the Scottish Rite Cathedral in San Antonio, TX, designed by Herbert Green and Ralph Cameron. 1924. Photo: James Dougherty 
each side, (f), at once gives a complete union of parts, so that an observer, if asked what he saw in (f) would answer, a border, or an ornamental band, and not, ten ovals, eleven dashes, and two lines" (Robinson, 1908:p.19,p.20).

"Some tools are available to the designer in pursuit of unity... For example, straight lines to give unity are used constantly in architecture in horizontal moldings (Robinson, 1908:p.20). These long uninterrupted horizontal lines visually hold vertical elements like columns in place and keep them from appearing ready to march away (Robinson, 1908: p.27). A firm baseline does this, and a cornice does it even more. Think pictorially primarily, structurally secondarily. The structural reason for horizontal lines is not important, other than that nothing should shock the judgment with illusion" (Robinson, 1908:p.27).

Robinson continues his discussion with additional important compositional principles that can be applied to imbue an architectural design with character while maintaining a strong sense of unity.

\section{Individuality vs Continuity}

Robinson next posits that the physical expression of unity can be divided into two primary categories, which correspond to opposite sentiments: individual and continuous.

Buildings which express individuality command attention and stand out from their context as focal. They typically feature verticality in their silhouette, and their height is greater than their width. Pyramidal and pointed forms generally express the most striking individuality. Pyramids possess individuality because all lines trend to a single point. After the pyramid, the tower has the most individuality. (Robinson, 1908:p.23,p.24).

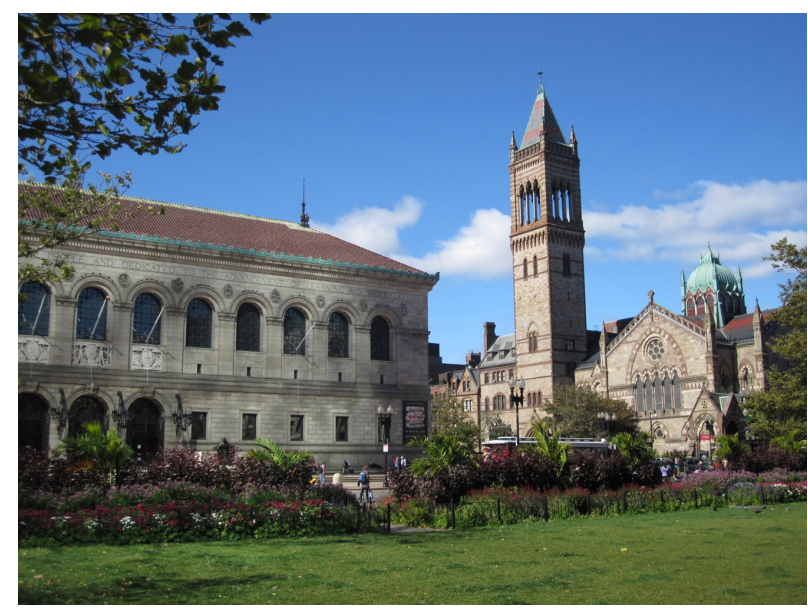

Fig. 5 The continuity of Boston Public Library (left) strikingly contrasted with the individuality of Old South Church (right). Copley Square, Boston USA. Photo: James Dougherty
Unity does not, however, require individuality; it can be achieved with continuity. Buildings in which width is greater than height lend themselves to continuous treatment. Buildings whose primary expression is horizontality, or continuity, tend to recede and blend into the urban fabric (Robinson, 1908:pp.22,p.23).

\section{Design Considerations When Expressing Individuality and Continuity}

Stronger horizontal lines should be used on a wide building to emphasize continuity. Stronger vertical lines should be used on a taller, slender building to emphasize individuality. (This can be reversed but requires a great deal of skill to be effective). It is difficult to gracefully combine a vertical mass in a horizontal building without creating a feeling of discord. By utilizing either a horizontal or a vertical treatment for the entire composition, unity can be achieved between disparate elements (Robinson, 1908:p.29,p.30.).

Powerful urban compositions can be created by skillfully utilizing both individual and continuous buildings. For any true aesthetic judgment of the productions of architecture and urbanism, we must judge them as we do a picture. Buildings must be judged in the context of their surroundings. Buildings expressing continuity and horizontality can be used to form a serene backdrop or frame. Striking results can be obtained by contrasting this placid backdrop with a focal building expressing individuality and verticality. This arrangement is seen, for example, in an Italian hill town whose otherwise plain silhouette is pierced by the campanile of a church. Any ordinary group of heterogeneous parts can be pulled together if one of them can be arranged as a tower around which the rest cluster (Robinson, 1908:p.25).

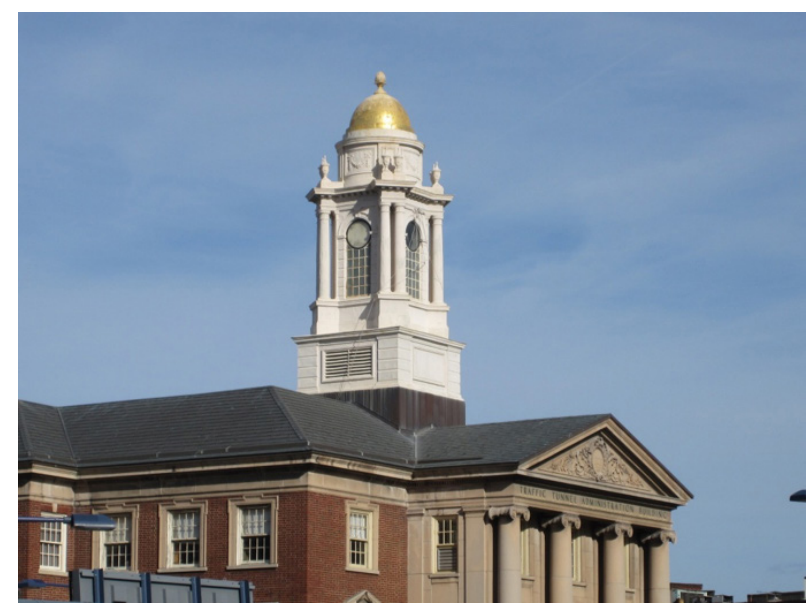

Fig. 6 The individual expression of the tower of the historic Tunnel Traffic Administration building designed by John M. Gray. 1931. Boston, MA, USA. Photo: James Dougherty 


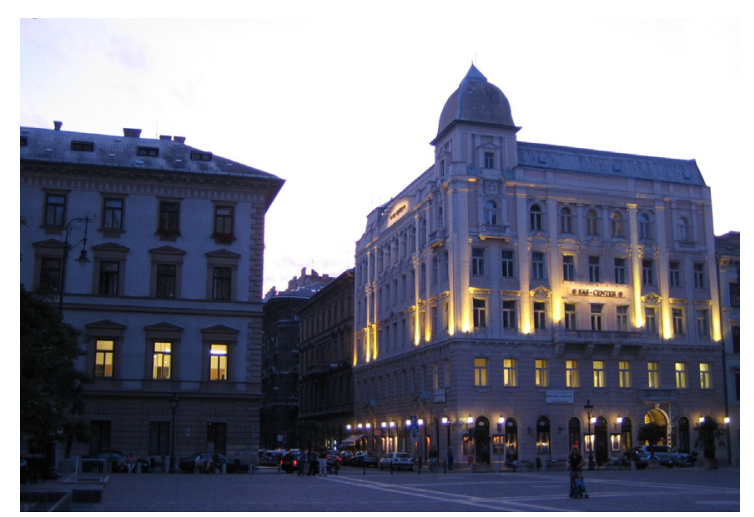

Fig. 7 The individual expression of a modest cupola strengthens the sense of unity among a collection of buildings on Budapest's Szent István tér. Photo: James Dougherty

A note of caution: an over-emphasis on horizontal forms can result in compositions without punctuation. When verticality, or individuality, is overly suppressed, the results are often perceived as boring and monotonous.

The un-modulated expression of continuity is often seen in the design of parking garages and is a reason why (in addition to the problem of their lack of active human uses inside) they often create an impression of bland monotony and can therefore seem to deaden a street scene.

\section{Hierarchy and Subordination}

Robinson next explains that a clear hierarchy of forms within a building or urban composition is key to achieving architectural unity. "When giving to each part of a building its relative importance, subordination should be accentuated to leave no doubt as to the leading motive" (Robinson, 1908:p.47,p.48).

Robinson goes on to describe three primary methods of hierarchy and subordination:

1. Difference in height - "This is the most effective and striking dimension by which importance may be added, as a taller building or architectural element will affect that most important of compositional lines, the silhouette" (Robinson, 1908:p.48,p.49).

2. Relative width - "A wider element will increase in prominence. Keep in mind that an increase in width must be accompanied by an increase in the height of a given motive, or similarity of form will suffer and a conflict between subordination of height and width occurs" (Robinson, 1908:p.50,p.52).

3. Projection of depth - "This typically has very little effect on subordination if elements are otherwise equal in height and width as this causes little or no

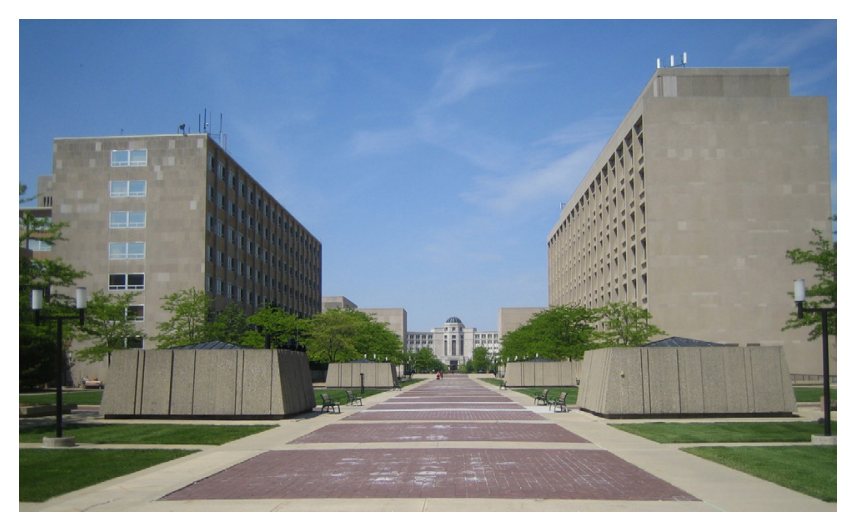

Fig. 8 An over-emphasis on unpunctuated horizontal expression typically results in a bland composition. Lansing, MI, USA. Photo: James Dougherty

modification of silhouette. Projection becomes critical, however, when subordinating and rendering distinct parts of different sorts. For example, when subordinating a continuous building element to an individual building element, it is useful to have the continuous part set slightly behind the individual part" (Robinson, 1908:p.53).

\section{Massing Variations}

Robinson then postulates that building compositions may be comprised of three hierarchical categories of forms: primary masses, secondary masses, and details (Robinson, 1908:p.59).

Primary masses are the largest forms in a composition. They are perceivable at a glance as the main body of a building, to which other smaller secondary masses and details may be added (Robinson, 1908:p.59).

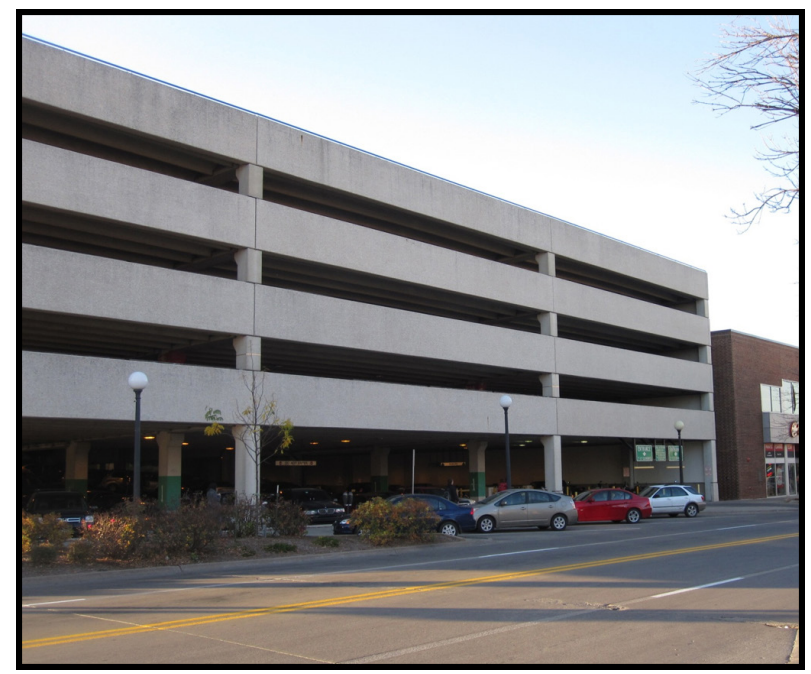

Fig. 9 Parking garages often suffer from over-emphasis on horizontal, continuous expression. Anne Arbor, MI. Photo: James Dougherty 


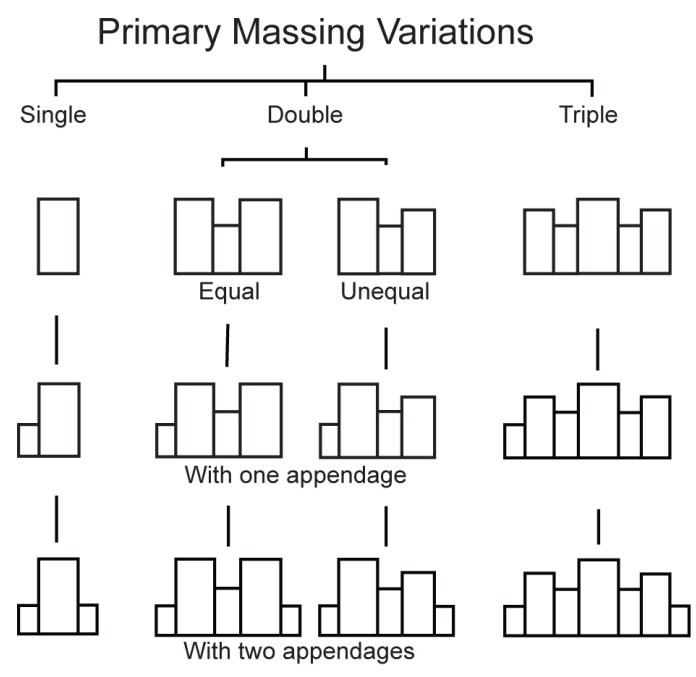

Fig. 10 Primary massing variations. After diagram in Architectural Composition by J. B. Robinson, 1908

Secondary masses, or appendages, may either project horizontally or vertically from primary masses. A secondary mass connecting two primary masses is called a link (Robinson, 1908:p.59).

After primary/secondary masses and links/appendages comes the third level of forms: details. These include doors, windows, chimneys, columns, brackets, arches, panels, cartouches, smaller turrets, and dormers (Robinson, 1908:p.62).

Robinson goes on to explain that "all buildings of character may be categorized into one of a limited number of combinations of single, double and triple primary masses, and associated secondary links and appendages" (Robinson, 1908:p.83,p.85)

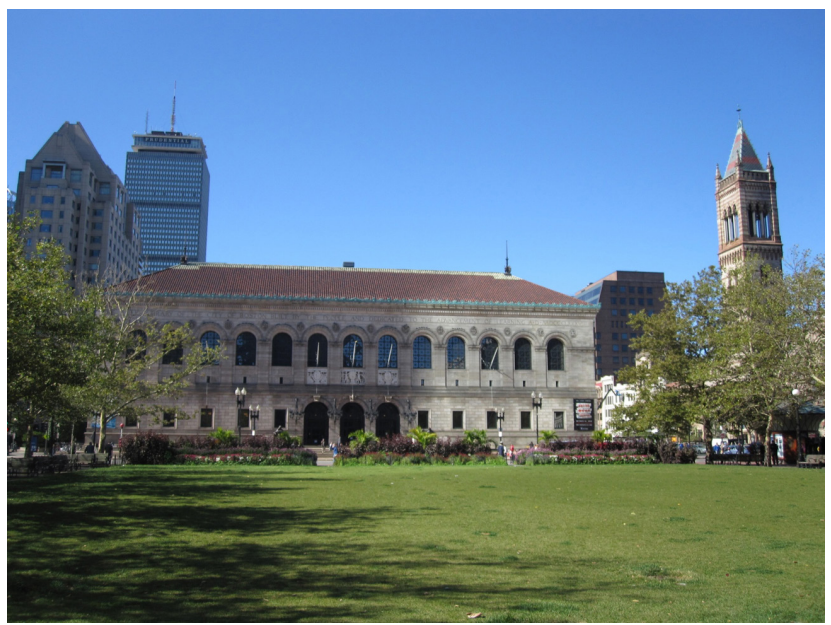

Fig. 11 The Boston Public Library, a sublime example of the unity of a single primary mass, designed by McKim, Mead \& White. 1895. Boston, MA, USA Photo: James Dougherty
Robinson then proceeds to delve more deeply into the important characteristics of these massing variations.

\section{One Single Primary Mass}

A building consisting of a single primary mass possesses unity in the highest degree. When it is possible to simplify a composition to a single mass, such as the Boston Public Library, do not give up the opportunity lightly (Robinson, 1908:p.63).

Note: When designing very large buildings of a single primary mass, beware of imposing artificial vertical breaks in the composition for the sake of visual variety. The articulation gained is usually outweighed by the loss of unity caused by breaking the horizontal lines and fragmenting the mass (Robinson, 1908:p.64).

\section{Two Primary Masses}

Two primary masses connected by a linking form will typically read as a single building form. The double primary forms must be combined via a visible link; otherwise, the resulting duality is troublesome like two doors, exactly alike, placed close together. The two primary forms must be similar, or discord will result. The two primary masses must be similar in shape, but need not be similar in size to achieve unity (Robinson, 1908:p.64,p.65).

Bilateral symmetry of two identical compositions is called "double composition" and requires great care for it to be effective. To unify a double composition, a single object, either a secondary mass or a detail, is often placed on the link between the two primary masses, usually at the center (Robinson, 1908:p.66,p.67).

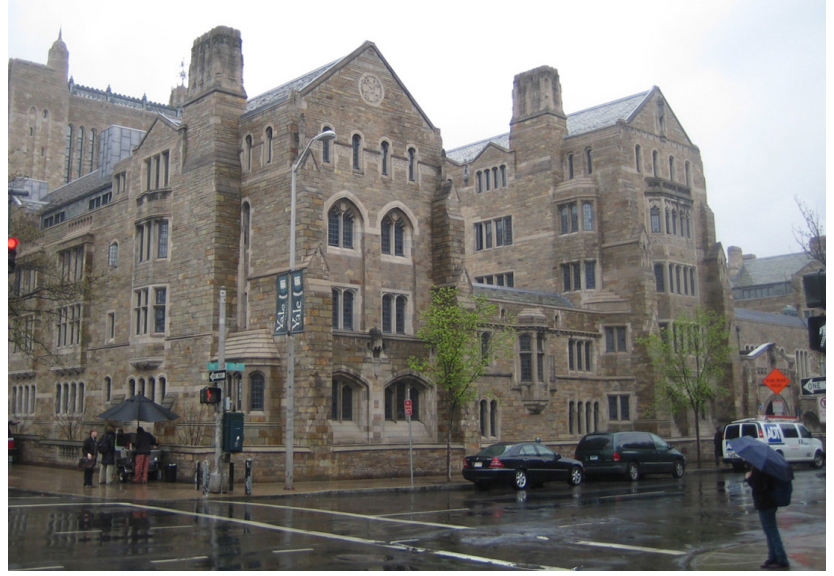

Fig. 12 Two similar, but non-identical masses, designed by James Gamble Rogers. 1917. Yale University, New Haven, CT, USA. Photo: James Dougherty 


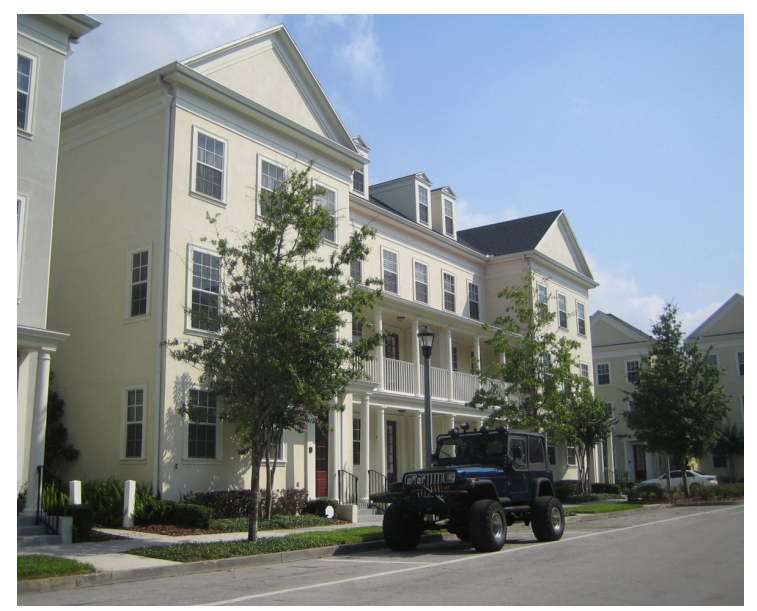

Fig. 13 Two primary masses connected by a link, designed by Geoffrey Mouen Architects. 2006. Baldwin Park, FL, USA.

Photo: James Dougherty

\section{Three Primary Masses}

Examples of compositions of triple primary masses, all the same size and all alike, almost never occur; however, examples where the central mass differs from the side masses are innumerably common. Most commonly, the central primary mass is larger than the two flanking primary masses (Robinson, 1908:p.73,p.74).

Compositions of three primary masses tend to read simultaneously like two separate compositions welded together: one of two masses joined by a link and a single mass with appendages (Robinson, 1908:p.76).

In general, the more similar the three masses are in size, the more similar they should be in appearance. On the other hand, no matter how great may be the difference in size, it is always possible to use a substantially similar treatment (Robinson, 1908:p.76,p.77)

Beyond three primary masses, the mind fails to grasp a group of objects as a unit and only perceives plurality. Groupings of four primary masses tend to coalesce into subgroups of two or three (Robinson, 1908:p.79,p.80).

\section{Secondary Masses}

Secondary masses must not be randomly applied but must be composed with careful attention to number, size, shape and dimensions. The form which is intended to be primary and the form which is intended to be secondary should clearly read as such. Secondary masses that possess individuality (vertical expression) fit most naturally on primary masses that also possess individuality (Robinson, 1908:pp.86-88).

A single secondary mass maximizes a sense of unity just like a single primary mass. A central classical portico

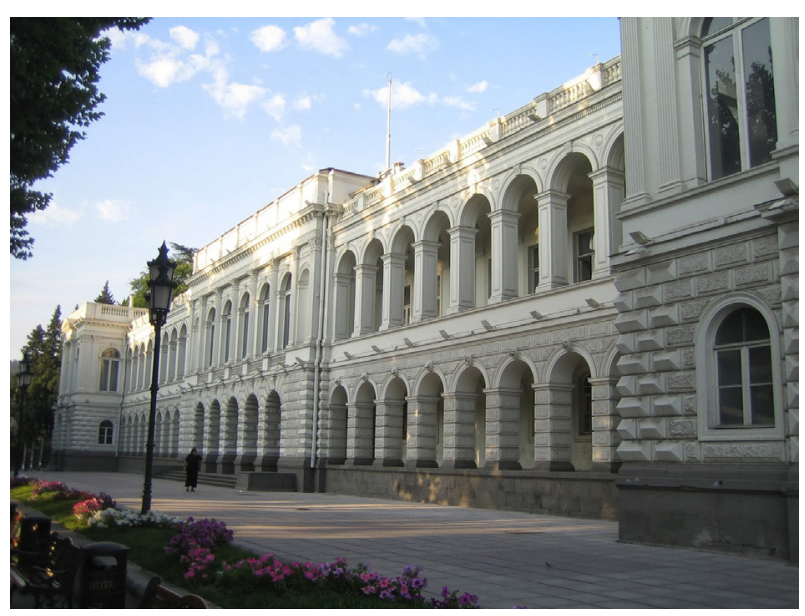

Fig. 14 Three similar primary masses connected by links. The central mass is largest. Viceroy's Palace, designed by Otto Jacob Simonsson. 1865. Tbilisi, Georgia. Photo: James Dougherty

or porch is the most common form of a dominant secondary mass (Robinson, 1908:p.88).

When grouping two or three secondary masses, all masses should be alike (if three masses, the central one can be larger). Secondary subordinate masses may also be composed in balanced asymmetry (Robinson, 1908:p.89,p.90).

Secondary masses generally follow the same rules as primary masses. An exception is that three secondary masses of the same shape and size may be freely used. Four or more equally sized and shaped secondary elements are aesthetically pleasing, especially when evenly spaced. They can be jarring if unevenly spaced. Four or more elements express unity through continuity rather than through individuality (Robinson, 1908:p.91).

\section{Details}

Details are minor architectural objects such as windows, door openings, panels, niches, columns, arches, etc. The rules for the number and composition of details are the same as for secondary masses. As with secondary masses, a single detail properly placed will often be sufficient to give unity to a whole composition. A single primary organizing detail is just as effective if placed asymmetrically or symmetrically (Robinson, 1908:p.99).

When grouping multiple details, such as columns in a colonnade, avoid changes in spacing (Robinson, 1908:p.102).

The arrangement of details follows the same principles as the arrangement of secondary masses. Division of a mass into two parts by details gives an impression of continuity. The division into one or three parts gives an impression of individuality (Robinson, 1908:p.103,p.104). 


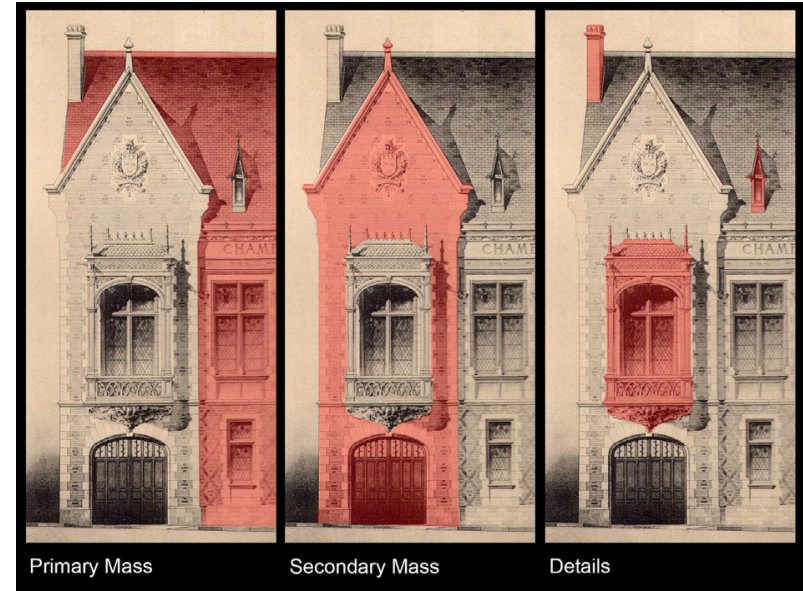

Fig. 15 Primary masses, secondary masses and details. Diagram by James Dougherty over an image from Les Concours Publics d'Architecture, Wulliam et Farge, Librairie Centrale d'Architecture, Paris 1895.

Endlessly creative combinations and variations are possible.

\section{Horizontal Layering}

Next, Robinson discusses how to begin articulating the masses by looking at big horizontal subdivisions first.

He states that, whatever the building style, some demarcation of the top of the building and the base is needed (Robinson, 1908:p.120). The design of public spaces is similar to the design of rooms. The size and proportion of height to width of a room are primary aspects of its character. The clear expression of the vertical extent of an exterior façade is similarly critical, as a given façade's perceived scale combines with that of adjacent buildings and those across the street to provide a sense of shape, enclosure, and proportion of the street or public space (Curtis, 1923:p.10).

Horizontal Division is primarily achieved in two ways:

1. Offset the plane of the façade by stepping back. (A note of caution: this can sometimes be problematic in effect as stepping back produces little or no shadow line, so only works well on elements such as towers, where the profile is visible) (Robinson, 1908:p.116).

2. Lines upon the façade created via shadows from moldings (Robinson, 1908:p.117).

After the base and top of the façade have been clearly demarcated, the wall surface itself may be subdivided by moldings in various ways to provide the building with its personal character. Robinson states that all buildings of character can be categorized into one of a

\section{Layering Variations}

Examples of horizontal subdivision can be grouped into one of the following categories.

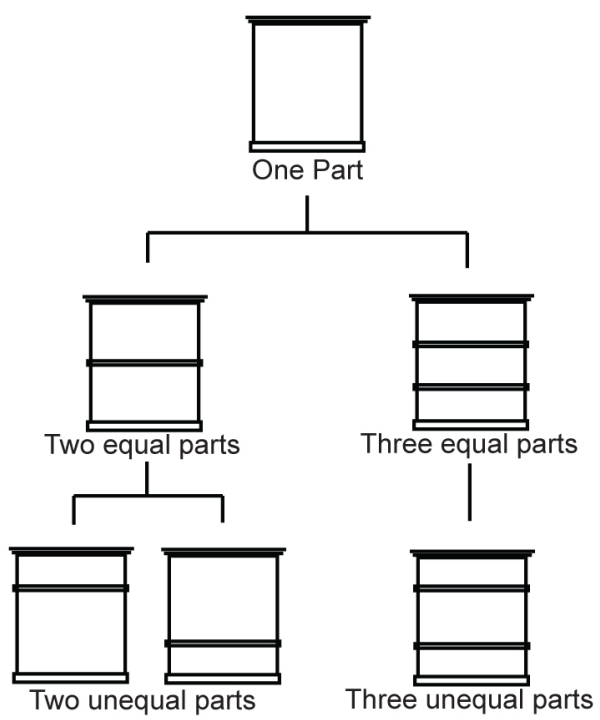

Fig. 16 Horizontal layering variations. After diagram in Architectural Composition by J. B. Robinson, 1908

limited number of combinations of horizontal divisions (Robinson, 1908:p.120).

First, it is possible that just the top and base of the façade are demarcated, with no further subdivision into layers (Robinson, 1908:p.123).

\section{Two Horizontal Layers}

Methods of horizontal division into two parts include:

- Division into two substantially equal parts,

- Top or bottom predominate very slightly, and

- Top or bottom may predominate greatly (Robinson, 1908:pp.121,p.125).

\section{Three Horizontal Layers}

Division into three parts includes:

- Three equal parts. (Many Italian Renaissance palazzos use this form).

- Three unequal parts.

- In buildings with pavilions - often three parts are used for pavilions, two parts for connectors (Robinson, 1908:p.122,p.125).

If we exceed two or three parts in our horizontal division, "we can make the results pleasing only by subordinating the additional parts to the two or three we have admitted 


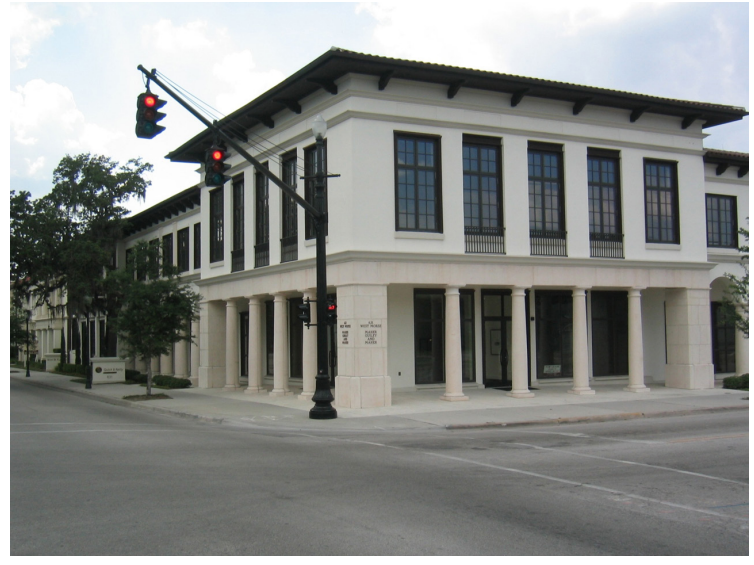

Fig. 17 Horizontal division into two equal layers in this classical revival design by Martin \& Vargas. 2003. Morse Blvd, Winter Park, FL, USA. Photo: James Dougherty

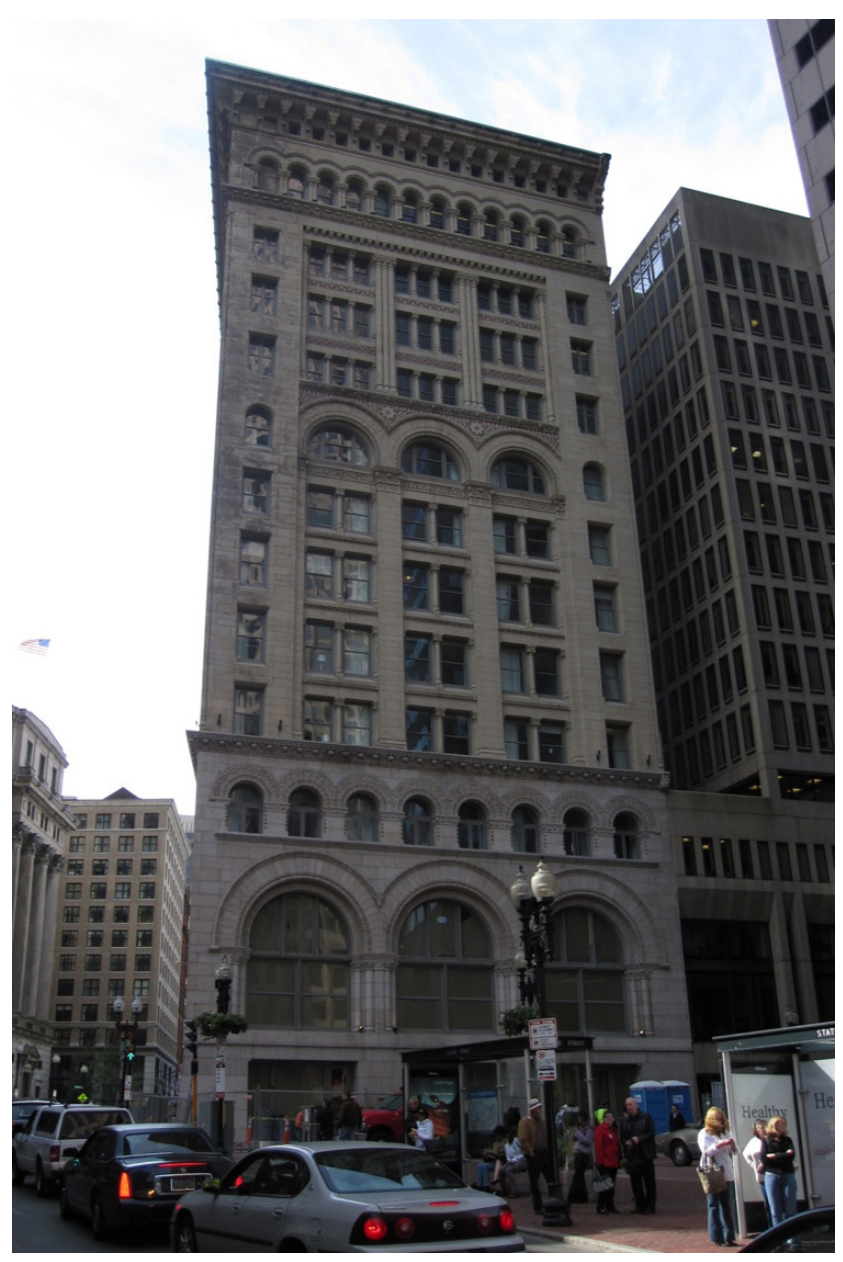

Fig. 19 Horizontal division into three unequal layers can be seen in the Ames Building a classic skyscraper designed by Shepley, Rhutan and Coolidge. 1893. Boston, MA, USA. Photo: James Dougherty

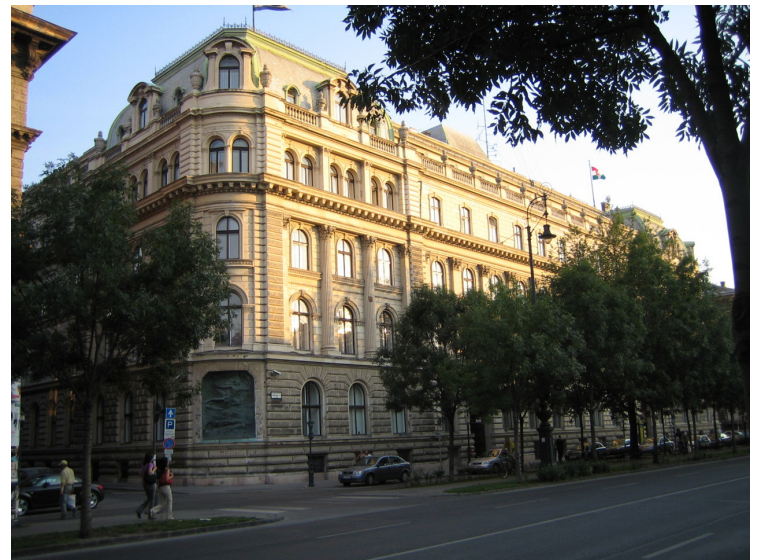

Fig. 18 Horizontal division into three unequal layers. Andrássy út, Budapest, Photo: James Dougherty

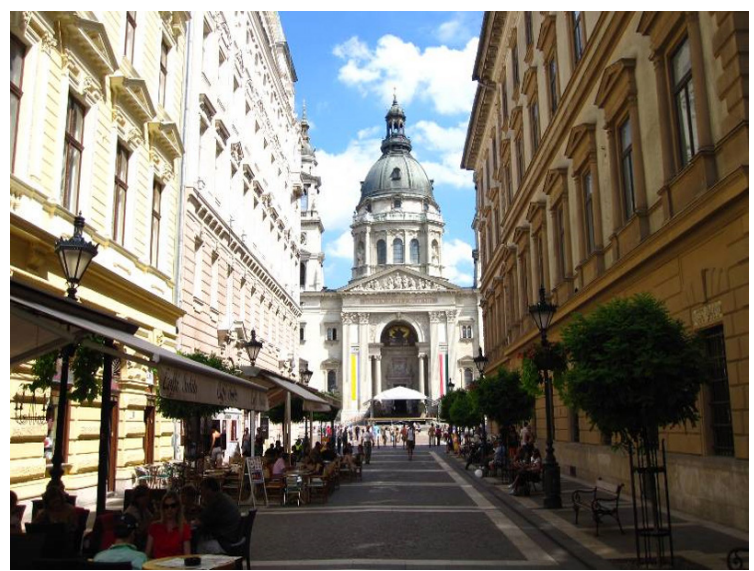

Fig. 20 Spokewheeling - in perspective, horizontal architectural lines become radials which converge dramatically at a vanishing point and reinforce the prominence of a focal building placed in the framed view. Szent István-Bazilika, Budapest, designed by Miklós Ybl. 1856. Photo: James Dougherty

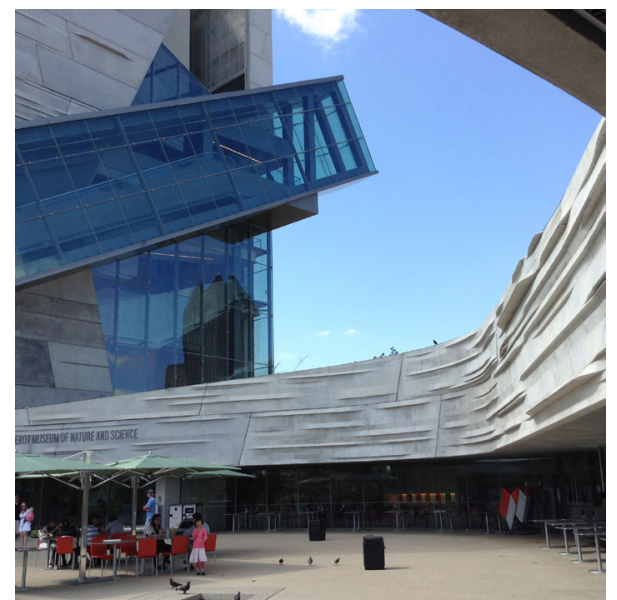

Fig. 21 Contemporary architecture, such as the Dallas Museum of Nature and Science designed by Thom Mayne and Morphosis Architects, often employs skewed horizontal lines. 2012. Photo: James Dougherty 
as our foundation. If we fail to do this, the whole composition becomes an unintelligible jumble of parts in which the eye discerns no fundamental unity of conception. With such subordination, we can handle any reasonable number of minor parts" (Robinson, 1908:p.126,p.127).

In tall buildings, the middle of the three divisions is typically the largest, as the building is divided into a base, shaft and capital - like a column (Robinson, 1908:p.123).

\section{Horizontal Lines Become Radial Lines When Viewed in Perspective}

A space such as the approach to the St. Stephen's Basilica in Budapest demonstrates an interesting and important characteristic of the horizontal subdividing lines employed in late $19^{\text {th }}$ and early $20^{\text {th }}$ Century architecture. These horizontal lines look static when seen in elevation, but when walking through an urban environment, these lines are seen in perspective, and they become dynamic. In fact, they become radials that point to any focal object that may inhabit a position at the end of the street. This enhances one of the most powerful compositional tools available to urban designers the framed view of a focal object (Loomis, 1947:p.46).

Incidentally, this explains the potentially disruptive visual effect of a building designed with skewed horizontals, as is often the fashion today. Such a building, while individually perhaps a pleasing sculptural shape, can inadvertently disrupt an urban composition if placed in a framing location where horizontal lines are meant to radiate from a framed focal structure (Loomis, 1947:p.47).

\section{Similar Rectangles}

Proportionate relations between parts.
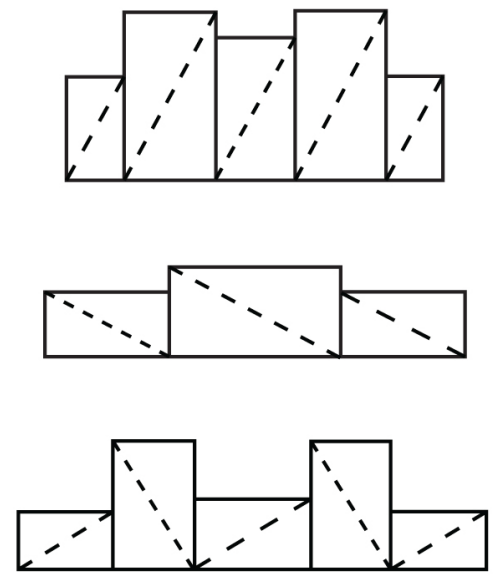

Fig. 22 Similar rectangles, an approach for achieving harmonious architectural proportions. After diagram in Architectural Composition by J. B. Robinson, 1908

\section{Proportion}

Robinson next discusses harmony that may be achieved through proportion within a building's façade. He is not a great proponent of particular "perfect" proportions such as the golden mean rectangle. As buildings are seen from many angles and often dramatically foreshortened, he feels that such perfect proportions are not particularly perceivable. Instead, he advocates for the echoing of similarly proportioned rectangles throughout a façade composition so that the façade will appear to be a cohesive form family (Robinson, 1908:p.137,p.138).

For example, the proportion of the large windows in Budapest's historic Stock Exchange building can be seen elsewhere in the façade, such as in the small windows above. Robinson believes that these echoed proportions do not need to be exactly the same to be effective as these rectangles are formed by the imprecise boundaries comprised of relatively broad shadow lines. They just need to be close to the same proportion.

Another way to create harmony within a structure is to coordinate the proportion of the roof shape with that of the body of the building. A low, wide building mass harmonizes well with a low, broad roof form. Taller, narrower building masses harmonize with taller, steeper roof forms (Robinson, 1908:p.158).

Robinson explains that this is of course just a "rule of thumb" and there are exceptions such as tall, slim Italianate towers which effectively harmonize with low, broad roofs (Robinson, 1908:p.163).

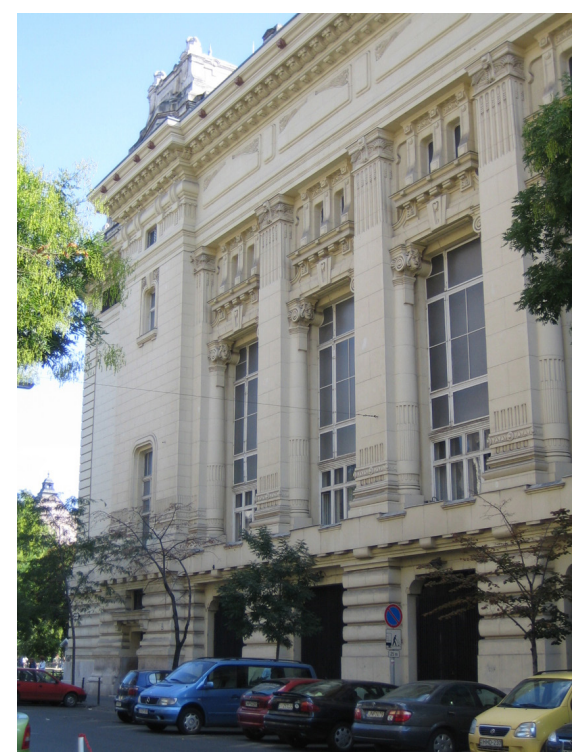

Fig. 23 Many similar rectangles can be observed in the façade of Budapest's historic Stock Exchange building on Szabadság tér, designed by Ignác Alpár. 1905. Photo: James Dougherty 


\section{Roof Forms}

Roofs should be proportionately related to the building below. Tall roofs complement vertical buildings' expression of individuality. Low, broad roofs emphasize continuity.
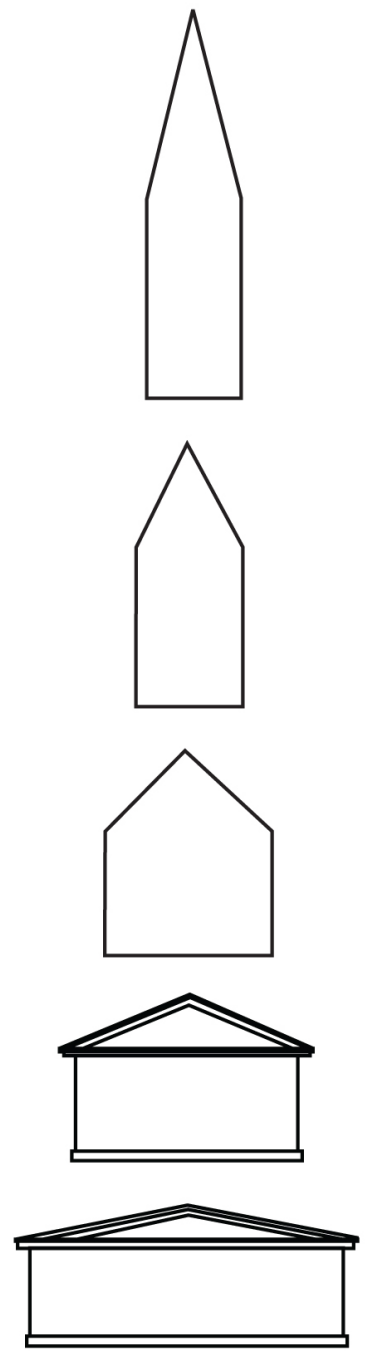

Fig. 24 Relative verticality of roof forms can be harmonized with the relative verticality of the building mass being roofed. After diagram in Architectural Composition by J. B. Robinson, 1908

\section{Similarity}

Robinson also states that echoing similar shapes within a façade can help generate a feeling of harmony. For example, arched windows combine well with domed forms to harmonize within a circular form family. Buildings can likewise employ similarly-proportioned pedimented forms at various scales to generate harmony. This could also be done, for example, with features like segmental arches, or horizontal balustrades (Robinson, 1908:p.35).

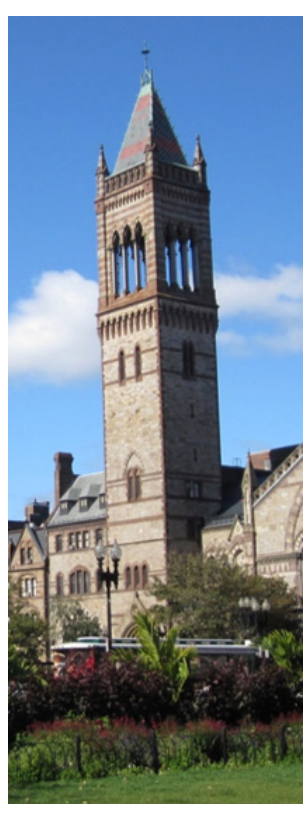

Fig. 25 A tall roof on a tall building mass, the tower of Boston's Old South Church, designed by Charles Amos Cummings and Williard T. Sears. 1873. Photo: James Dougherty

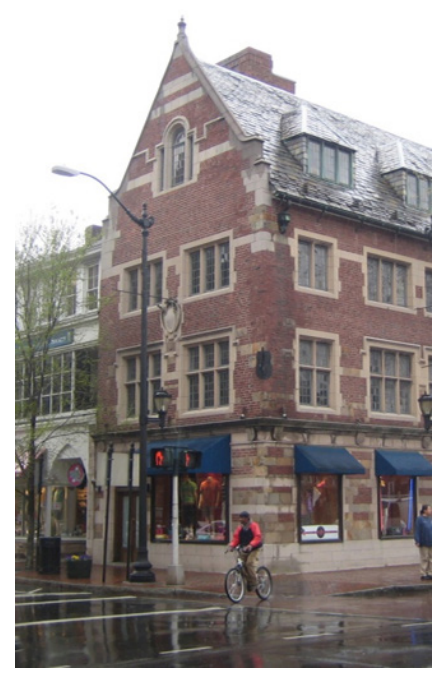

Fig. 26 A moderately steep roof on a moderately vertical building mass, designed by Jacob Weinstein. 1927. New Haven, CT.

Photo: James Dougherty

\section{Apparent Structure}

Lastly, a principle discussed by Robinson and also a great deal by other late $19^{\text {th }}$ and early $20^{\text {th }}$ Century architectural writers such as Nathaniel Cortland Curtis, JV Van Pelt and John Harbeson is that of "apparent structure". This is the visual expression of stability by aligning the solid portions of a façade on unbroken structural centerlines which extend from the top of a structure firmly to the ground (Curtis, 1923:pp.120-123; Harbeson, 1927:pp.19-25). 


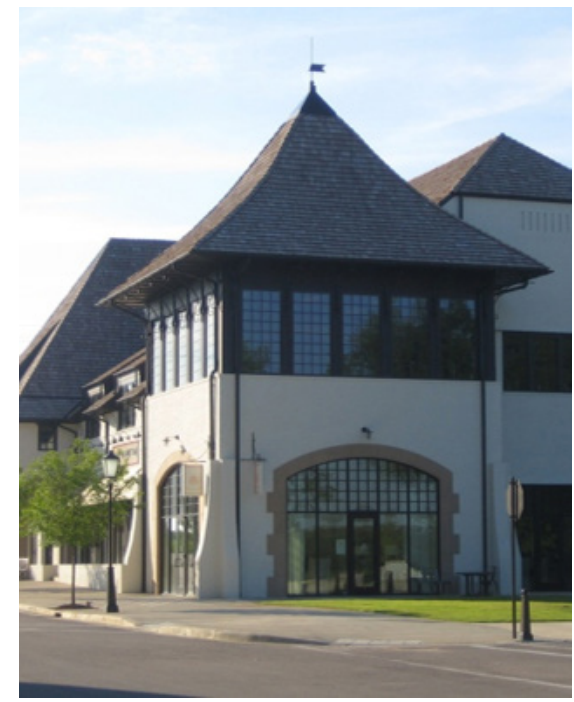

Fig. 27 A fairly low roof on a fairly squat building mass. Hampstead, Montgomery, AL, designed by Gary Justiss. 2004. Photo: James Dougherty

Interestingly, in contrast with architecture designed in the late $19^{\text {th }}$ and early $20^{\text {th }}$ Century, in contemporary architecture there is often an intentional avoidance of the expression of apparent structure. Forms are often designed to hover, with a reduced or sometimes entirely invisible means of structural support. This is done for a variety of compositional reasons - sometimes to make forms appear gossamer and ephemeral, and sometimes to make them appear ominously on the brink falling. This can be a powerful architectural tool to generate an emotional reaction, such as delight or unease, from a viewer.

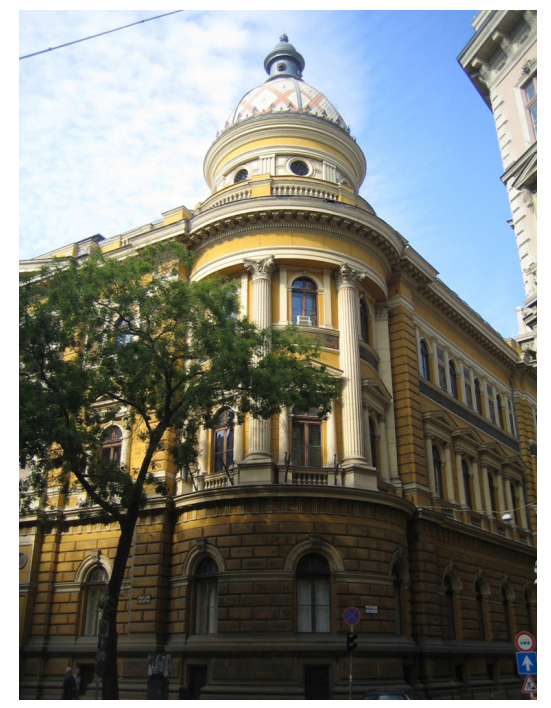

Fig. 29 Circular forms are echoed throughout the façade and plan of the ELTE University library on Budapest's Ferenciek tere, designed by Antal Skalnitzky. 1876. Photo: James Dougherty

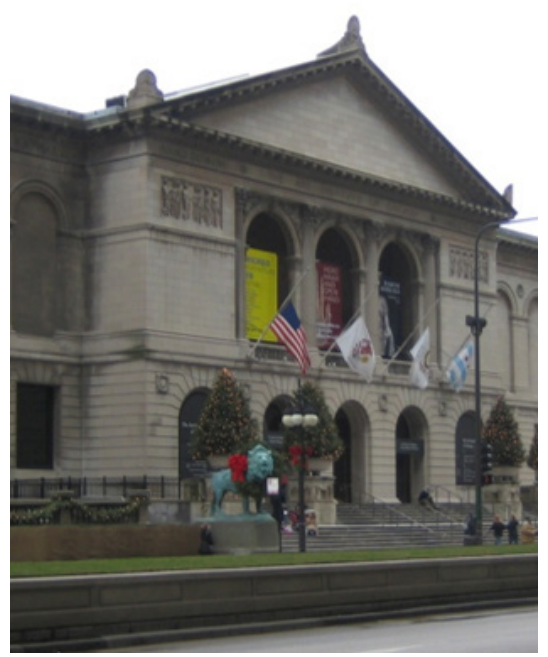

Fig. 28 A low pediment on a horizontally proportioned building. Art Institute of Chicago, designed by Shepley, Rhutan and Coolidge. 1893. Photo: James Dougherty

While architecture expressing weightlessness can be beautifully expressive, observations of immersive urban environments designed in the late $19^{\text {th }}$ and early $20^{\text {th }}$ Century teach us that care should be taken about the expression of apparent structure when composing a new structure to fit into an urban context. If an urban context is designed to express stability through the visual carriage of the full force of gravity, a new structure which is inserted that expresses a reduced visual effect of gravity can sometimes by contrast appear structurally improbable and tectonically untrustworthy, therefore creating a discordant effect for the viewer.

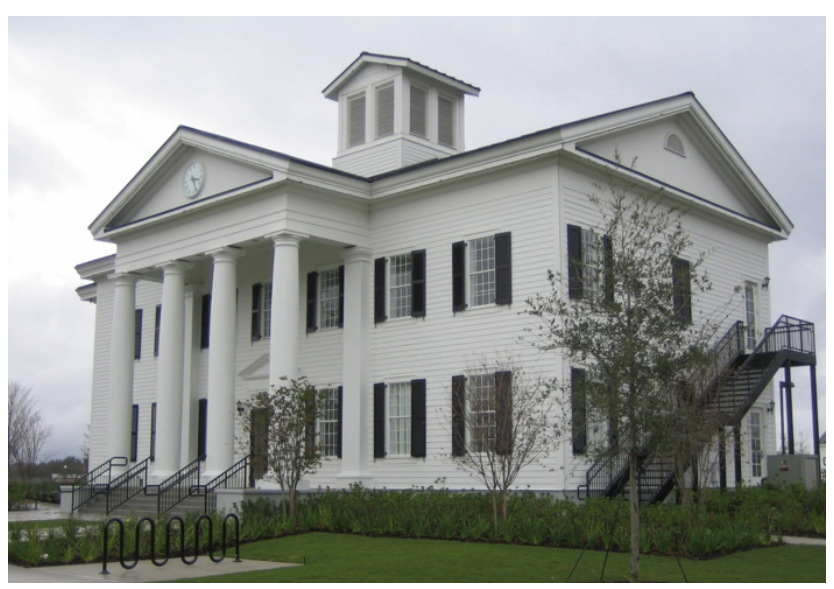

Fig. 30 Triangular pedimented forms are echoed throughout the design of this classical revival meeting hall in Orlando, FL's Baldwin Park neighborhood, designed by Geoffrey Mouen Architects. 2006 Photo: James Dougherty 


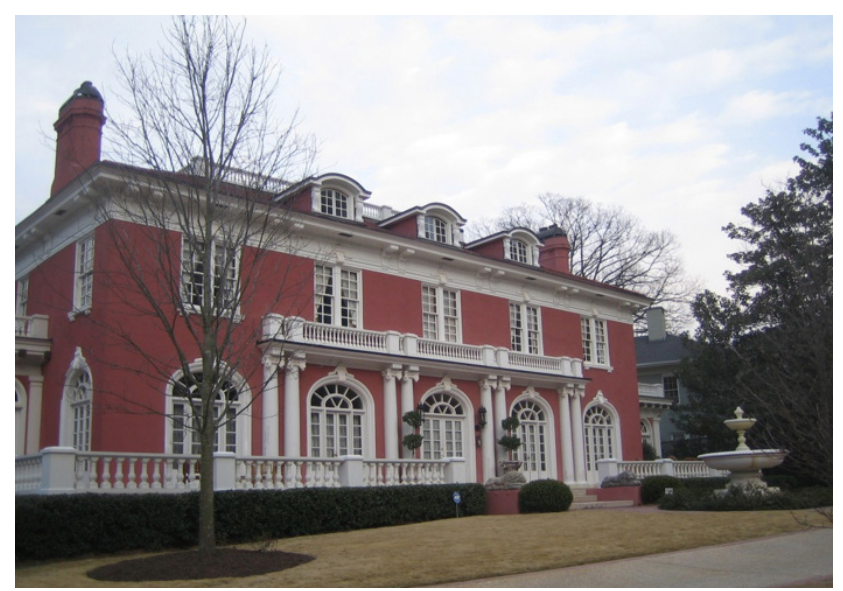

Fig. 31 Elliptical arch forms are echoed throughout the design of this building in Atlanta, GA's Ansley Park neighborhood by Walter T.

Downing. 1910. Photo: James Dougherty

To clarify this concept of the visual expression of carriage of gravity, it is helpful to think of a building standing on a scale to measure its weight. Buildings of the late $19^{\text {th }}$ and early $20^{\text {th }}$ Century tended to visually express the full weight of their materials. A brick appeared to weigh $100 \%$ as much as a brick. This weight was visually carried firmly to the ground by the design of the façade.

Contemporary architecture experimented with lighter expressions as can be seen in structures such as the High Museum in Atlanta, GA by Richard Meier. Like early Modernist buildings such as the Villa Savoye by Le Corbusier, the High Museum lifts masses upon slim pilotis and consequently gives them a feeling of lightness.

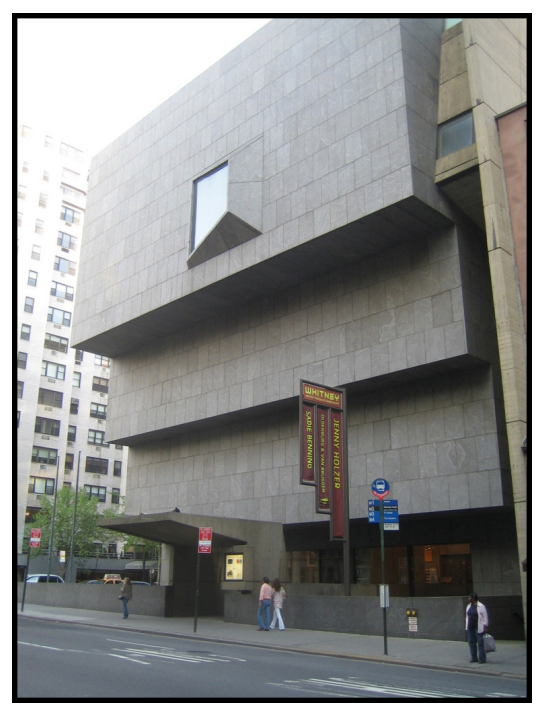

Fig. 33 A deliberate sense of foreboding and unease is communicated by the heavy, visually unsupported masses of Marcel Breuer's MET museum building in Manhattan, NY. 1966. Photo: James Dougherty

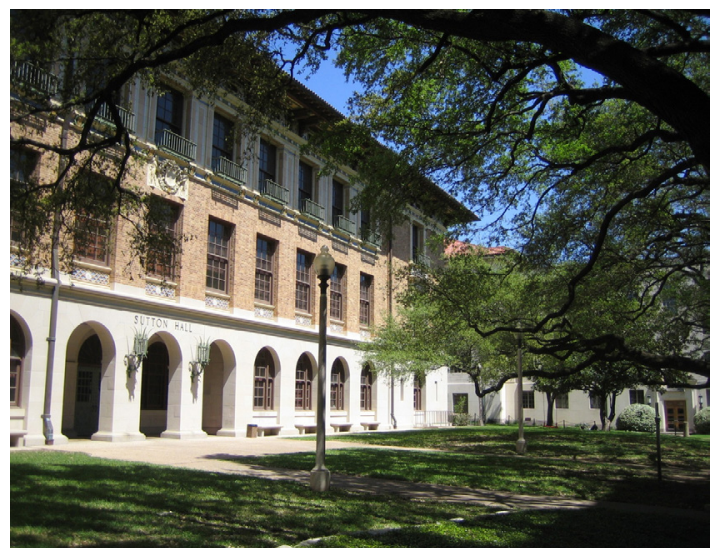

Fig. 32 A sense of visual stability is achieved by extending structural centerlines clearly from the roof all the way to the ground in this building on the University of Texas' Austin campus, designed by Cass Gilbert. 1911. Photo: James Dougherty

Other contemporary structures display experiments with even further reductions in apparent weight - dematerializing facades into shimmering planes of ephemeral light.

\section{Analyzing Building Facades Using Robinson's Design Principles - A Step-by-Step Method}

The framework of John Beverley Robinson's compositional principles summarized above can be used to analyze and visually digest the complex facades of the late $19^{\text {th }}$ and early $20^{\text {th }}$ Century. When first seen, such facades can appear to our eyes extraordinarily complex and glittering with detail - where does one start?

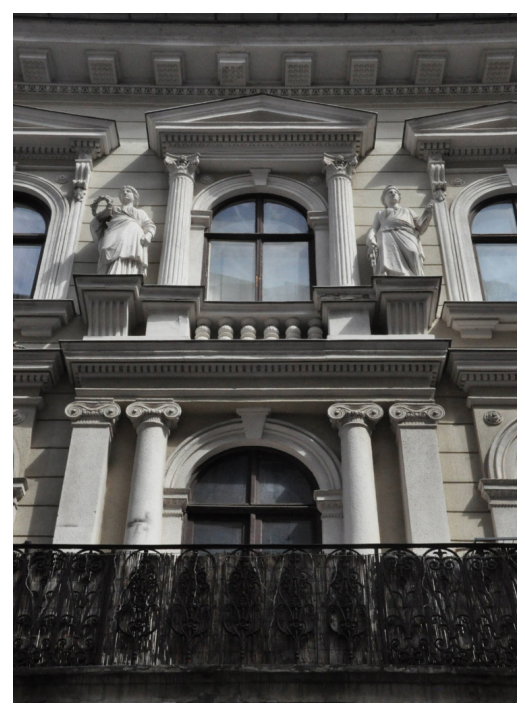

Fig. 34 Late $18^{\text {th }}$ and early $19^{\text {th }}$ Century architecture evolved from simple, early post and beam structures. It's ornament and details are derived from an aesthetic desire to express structural stability Photo: James Dougherty 


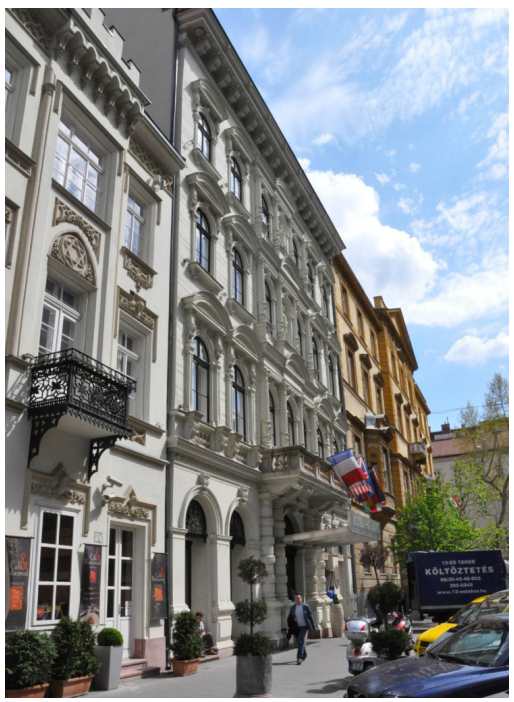

Fig. 35 The columns and entablatures on the faęade of Budapest's President Hotel elegantly express the visual carriage of the building's weight to the ground. Photo: James Dougherty

Using Robinson's various principles of design, such facades are not so insurmountably complex after all.

1. First, we identify the primary mass which is typically the tallest and largest form, to which subsequent masses may then be attached.

2. And then we identify the secondary masses.

3. And the smaller appended masses.

4. Then the even smaller details.

5. Then we proceed to identify the pattern of horizontal layering.

6. And the rhythm of vertical structural centerlines.

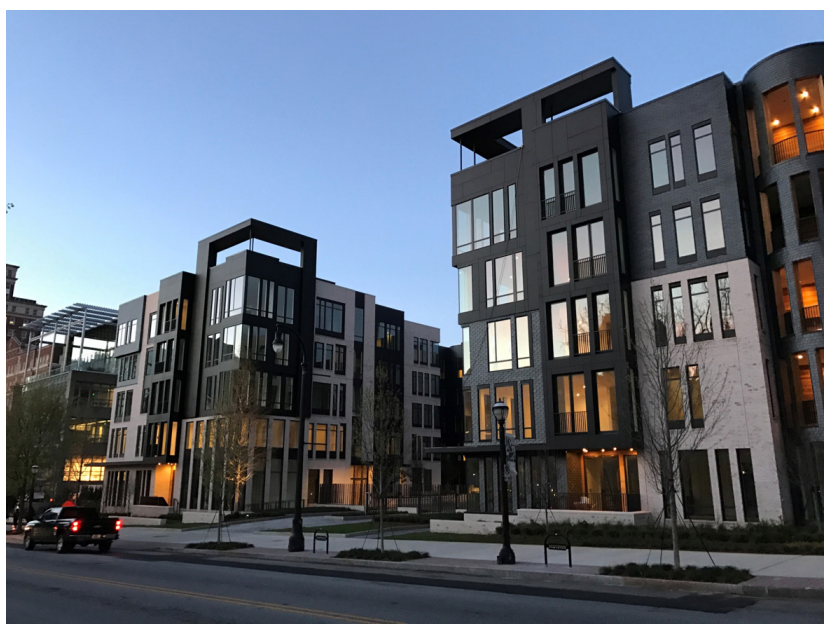

Fig. 37 Structural centerlines are intentionally discontinuous in the shifting masses and planes of the façade of this apartment building on Atlanta, GA's Peachtree St NE designed by Mack Scogin Merrill Elam Architects, 2015. Photo: James Dougherty

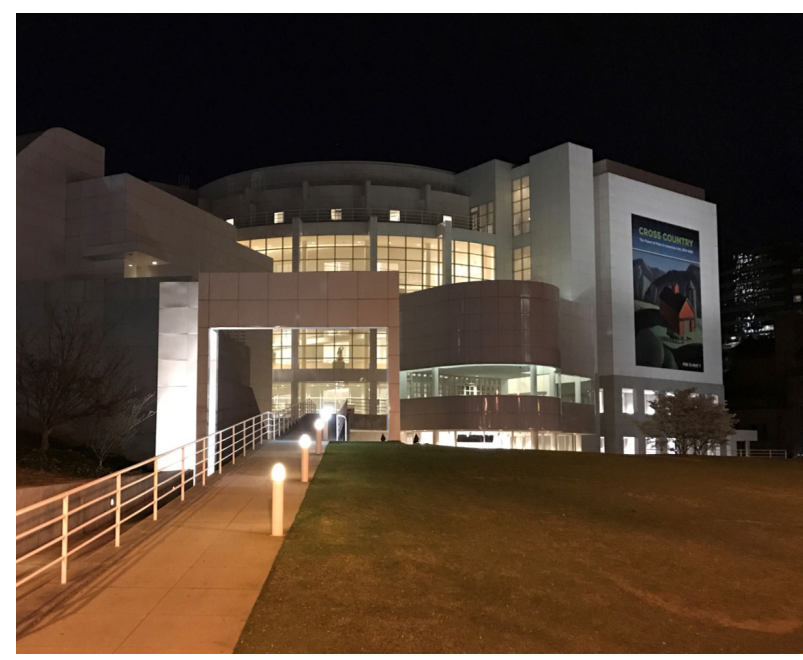

Fig. 36 With its bold masses supported by very slender columns, Richard Meier's High Museum in Atlanta, designed in 1980, visually expresses lightness and appears to exist in a world of reduced gravity. Photo: James Dougherty

7. The structural centerlines alternate with a rhythm of void centerlines.

8. Finally, the pattern of windows and door openings are symmetrically arranged about the void centerlines.

This method generally starts with large shapes first and then proceeds to subdivide them into smaller shapes in a methodical way. What previously seemed a very complex façade is, by this procedure, easily digestible into a series of quite straightforward components.

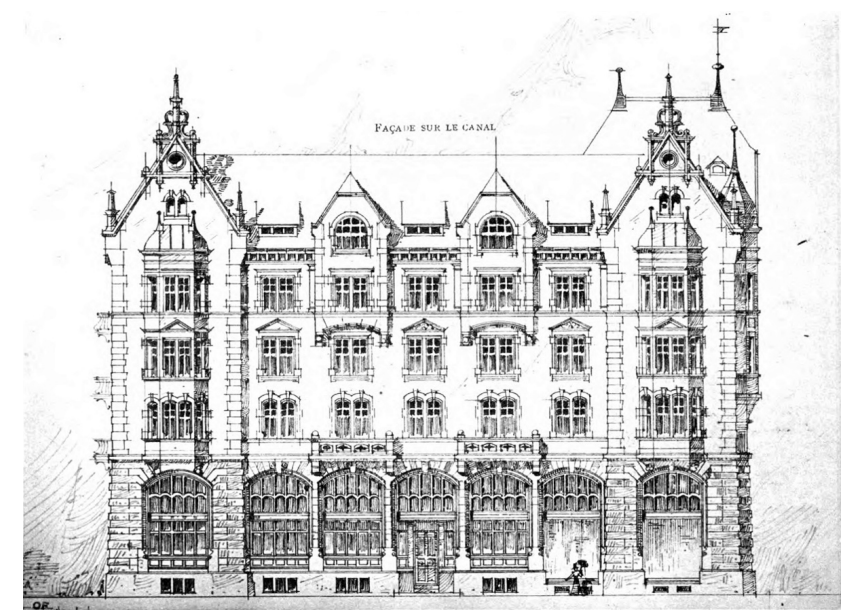

Fig. 38 A finely-articulated late $19^{\text {th }}$ Century façade from Les Concours Publics d'Architecture, Wulliam et Farge, Librairie Centrale d'Architecture, Paris 1895. 


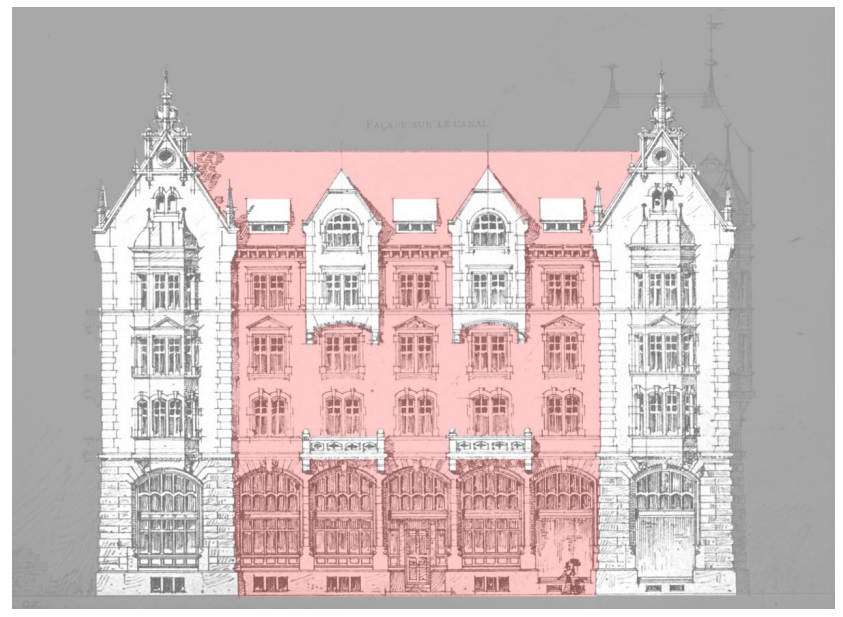

Fig. 39 The primary mass.

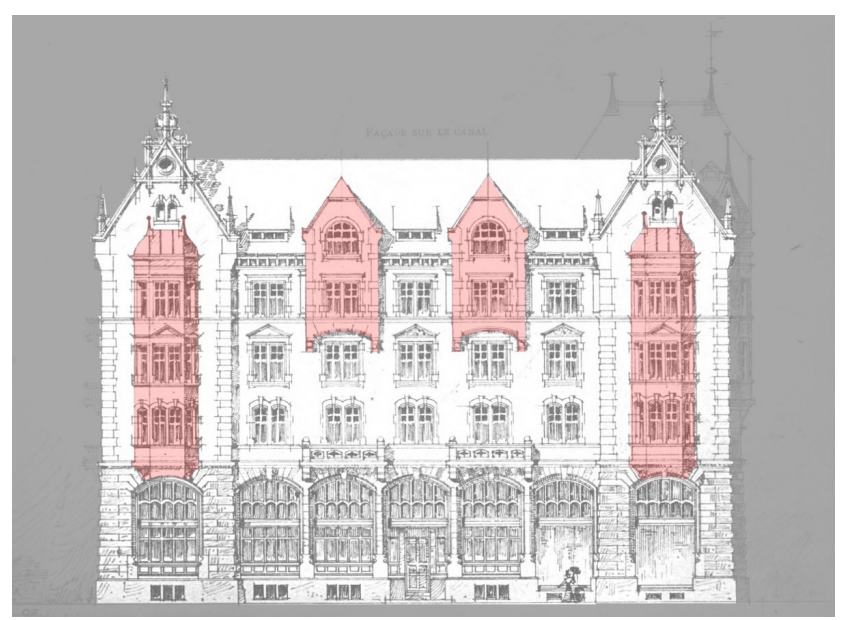

Fig 41 Appended masses.

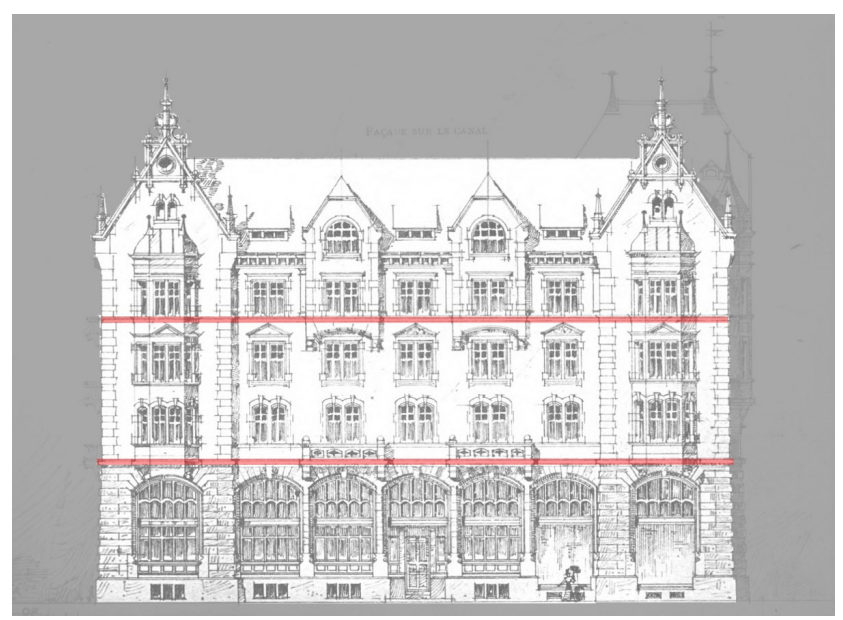

Fig. 43 Expression lines subdividing the façade into horizontal layers.

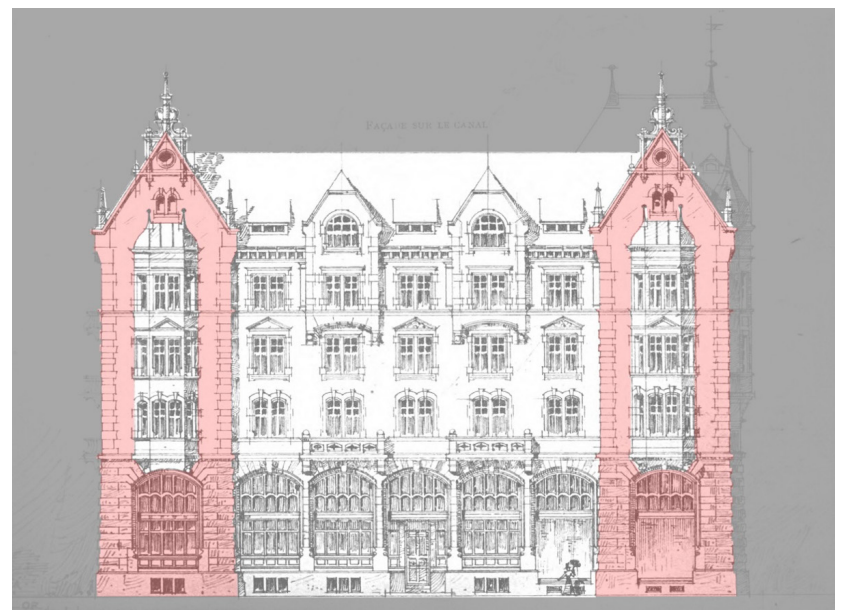

Fig. 40 These two secondary masses bookend the façade composition

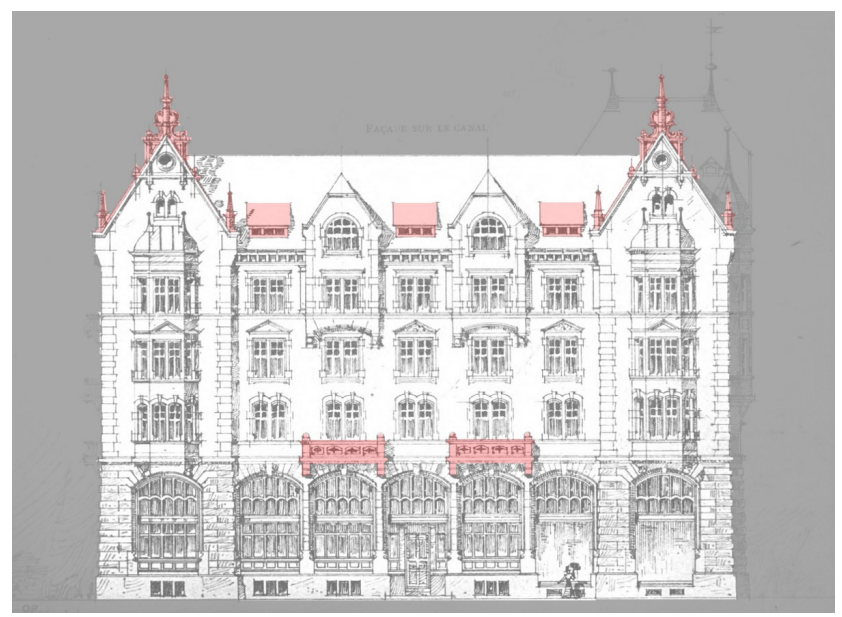

Fig. 42 Details.

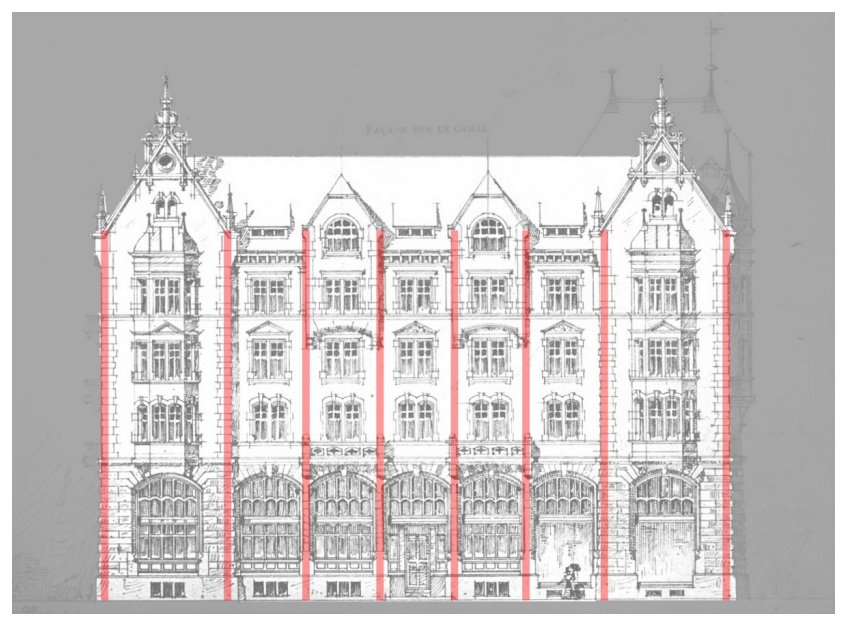

Fig. 44 Vertical structural centerlines. 


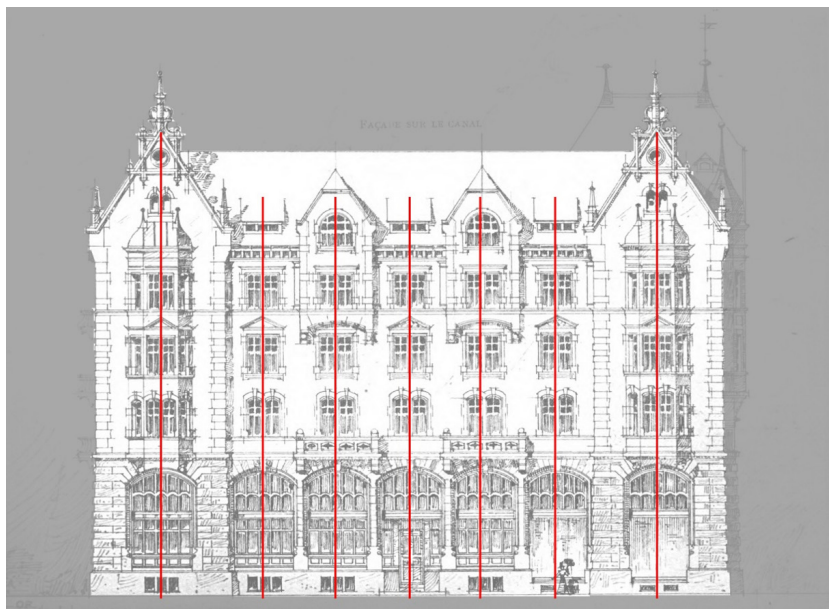

Fig. 45 Vertical void centerlines.

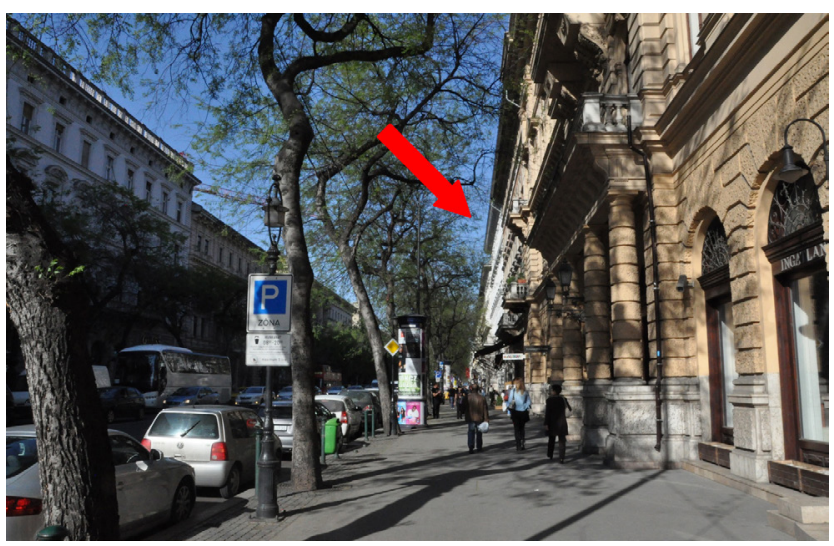

Fig. 47 A late $19^{\text {th }}$ Century building on Budapest's Andrássy út, seen from a great distance. Photo: James Dougherty

Once this method of compositional subdivision is understood, it then becomes possible to proceed as designers in the opposite direction - to creatively progress from a blank sheet of paper to the composition of a new façade in the late $19^{\text {th }}$ and early $20^{\text {th }}$ Century manner.

\section{3 "Nested" Architectural Compositions}

As we have seen in Robinson's work, late $19^{\text {th }}$ and early $20^{\text {th }}$ Century façades consist of compositions within compositions. Large overall parti are continually subdivided to form smaller compositions right down to the details (Varon, 1916:p.22,p.23:Plate XVII). This is a bit like classic Russian "nested dolls" where one exists within the next.

Importantly, this approach of nested compositions is not just an abstract design approach. It actually corresponds to the way these buildings are perceived as one moves through urban space and helps to explain why these urban environments often feel so magical.

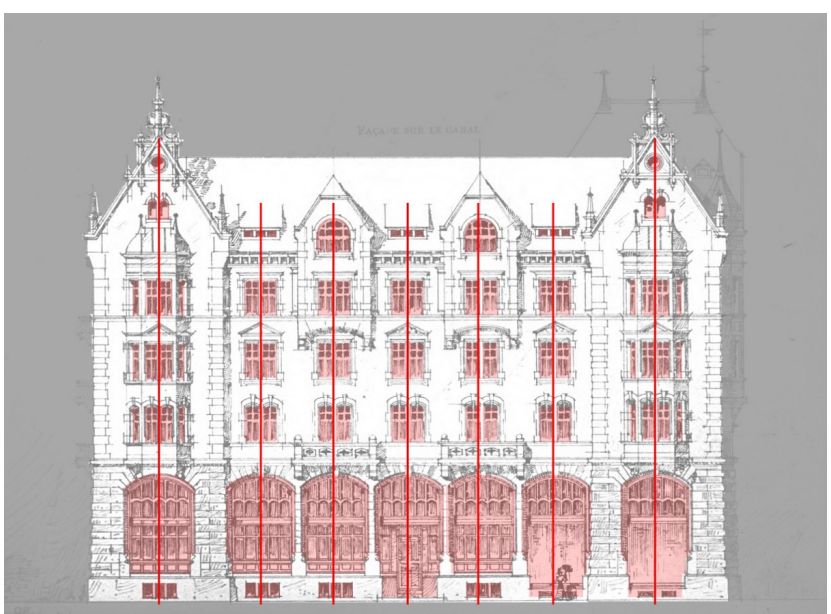

Fig. 46 Fenestration pattern, arranged about the void centerlines.

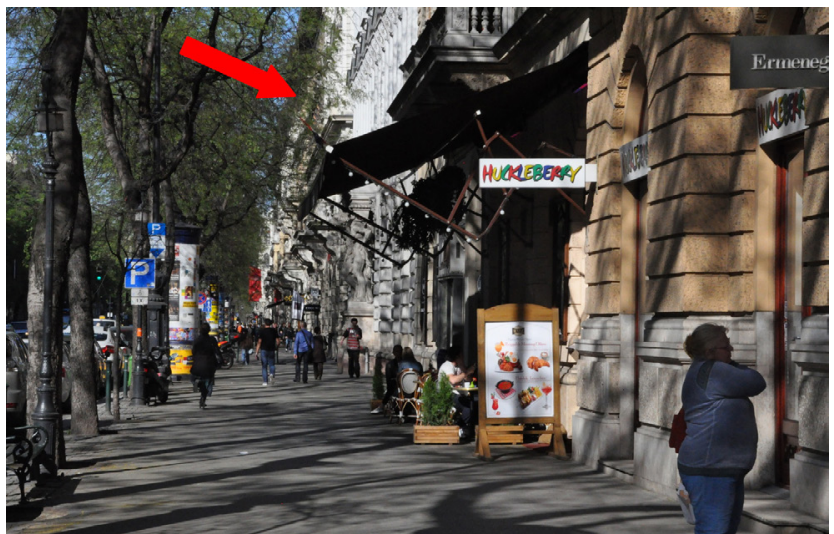

Fig. 48 Moving closer, the view from 30 meters. Photo: James Dougherty

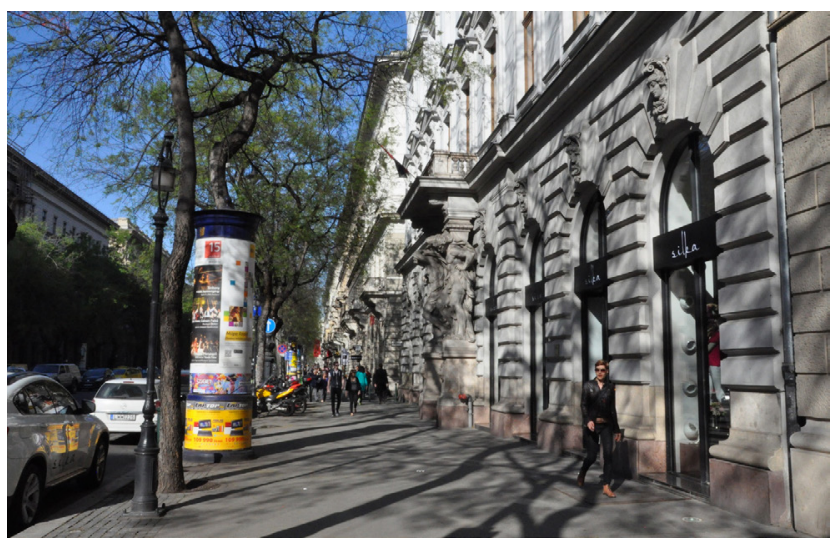

Fig. 49 Closer still, from 10 meters. Photo: James Dougherty

Seen from far away, only the largest aspects of a building's parti are visible. Just the overall mass and a faint sense of horizontal layering. Smaller details cannot be perceived at this distance (Varon, 1916:Plates XVI, XVII). 
Proceed a bit closer, perhaps a half block away, and the horizontal layering can now be clearly seen. At 30 meters, a sense of the vertical rhythm of structure and void centerlines can now be perceived.

At 10 meters, the pattern of vertically stacked structure and voids is fully perceivable, and architectural details now begin to reveal themselves.

Closer still, at perhaps six meters, the overall form of sculptural details of the façade can now be seen clearly. Still closer, and finer details of sculptural arrangements can be seen.

It is not until one is just steps from a façade that the final level of detail is revealed. This unveiling of layers of composition one within the next as one approaches a building helps to propel one through urban spaces comprised of such buildings. The parti of these buildings seen at a great distance is typically quite simple, and the highest degree of sculptural wonderment is reserved for the arrival right in front of the building. In an urban environment composed of many such buildings, this experience of unveiling layers of composition follows one moving through the urban space. The viewer is thus continuously surrounded by a moment of maximum wonderment.

David Jacob Varon, in his book Indication in Architectural Design, discusses this convergence between

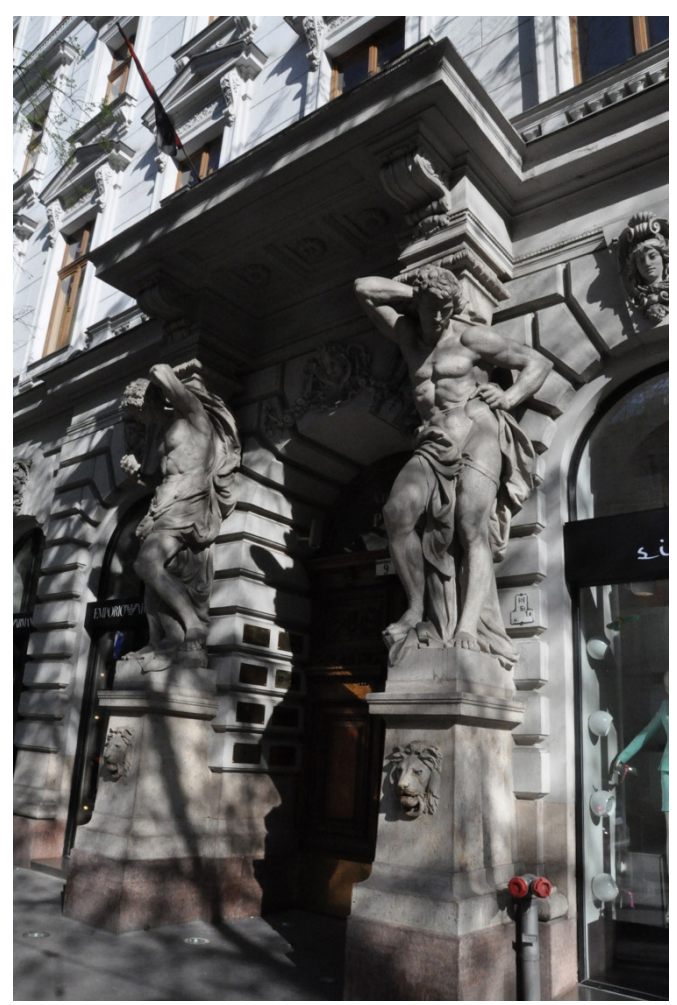

Fig. 50 From 4 meters. Photo: James Dougherty the design method of buildings of the late $19^{\text {th }}$ and early $20^{\text {th }}$ Century from large compositional parti through subdivisions to the details, and the experience of the unveiling of levels of detail as one approaches a composition (Varon, 1916:p.22,p.23:Plate XVII).

This awareness of different levels of composition perceivable at different distances can also be seen in classic Beaux-Arts Analytique drawings produced during the late $19^{\text {th }}$ and early $20^{\text {th }}$ Century, which represent a building at various distances by drawing it at different scales (Harbeson, 1927:pp.19-25).

\section{Contemporary Failures to Employ Nested Compositions in Architectural Design}

When viewing many of our contemporary urban buildings from multiple distances, a problem often becomes evident. These buildings are fine when viewed from far away. They demonstrate well-articulated overall massing and horizontal subdivisions.

As we get closer to the building however, an interesting thing happens. The subdivision of compositions into finer degrees of detail ceases.

This becomes more evident the closer to the building we move. When we are right in front of the building, where the buildings of the late $19^{\text {th }}$ and early $20^{\text {th }}$ Century tend to reveal

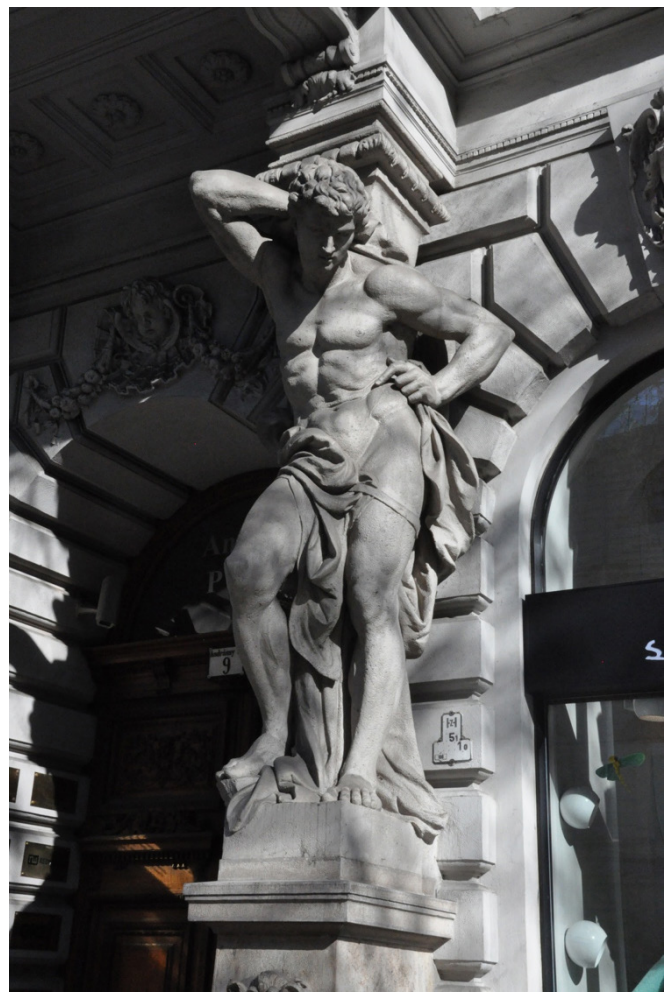

Fig. 51 Finally, standing on the sidewalk immediately in front of the building. Photo: James Dougherty 


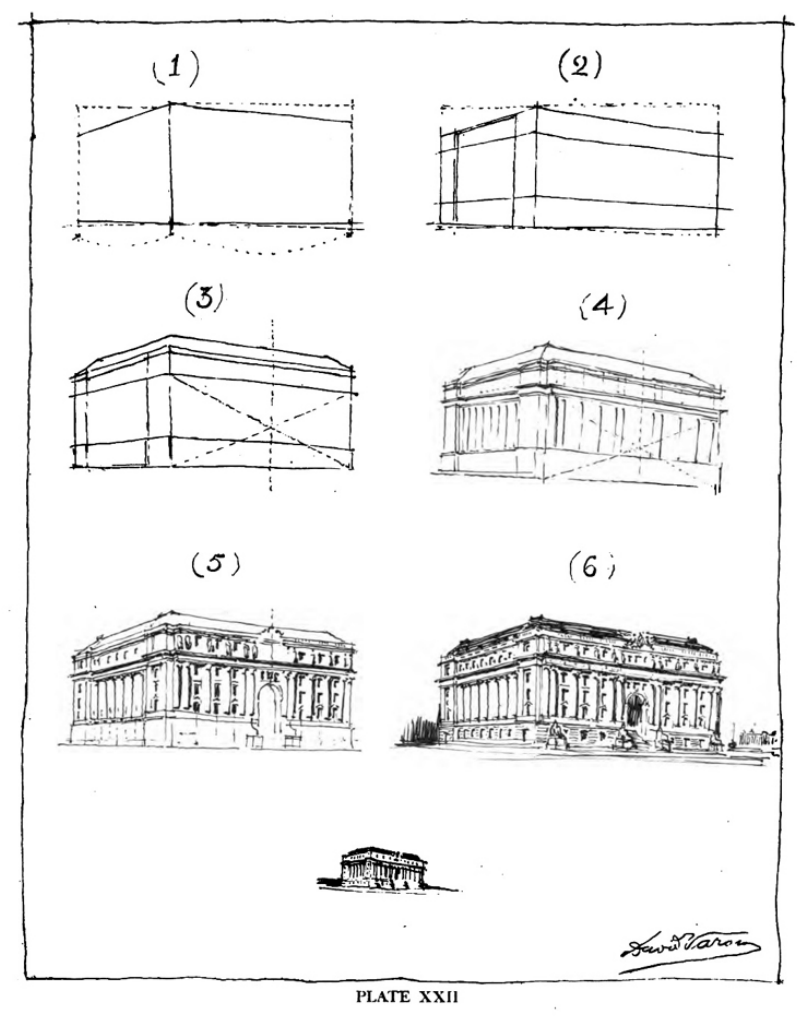

Fig. 52 Developing an architectural composition from the large masses to the small details by subdividing forms. From Indication in Architectural Design by David Jacob Varon, 1916

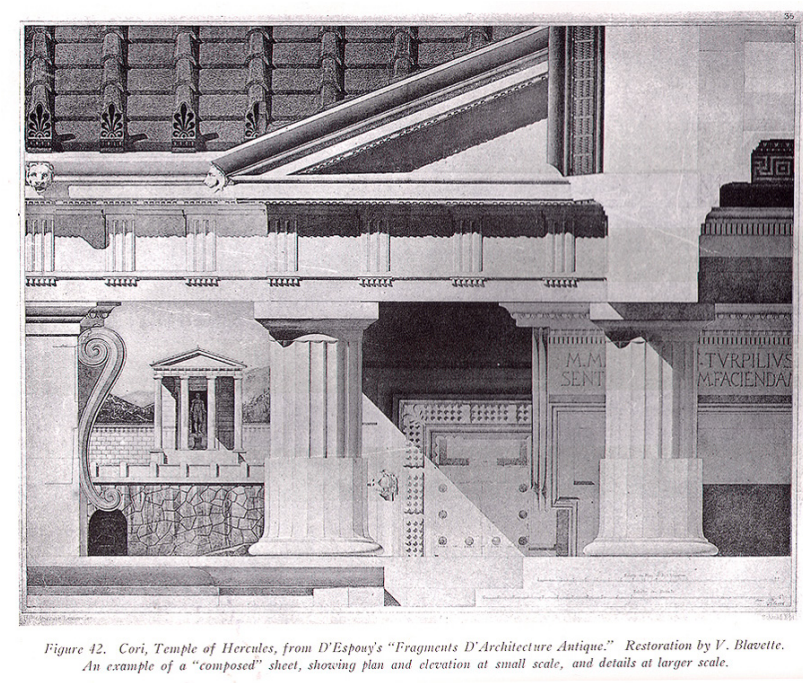

Fig. 54 Beaux-Arts analytique drawing. From The Study of Architectural Design by John Harbeson, 1927.

their moment of maximum wonderment, contemporary buildings unfortunately often confront us with blankness.

Just as a nurturing attention to compositional detail followed us as we moved through the urban spaces of the late $19^{\text {th }}$ and early $20^{\text {th }}$ Century, a feeling of blankness and

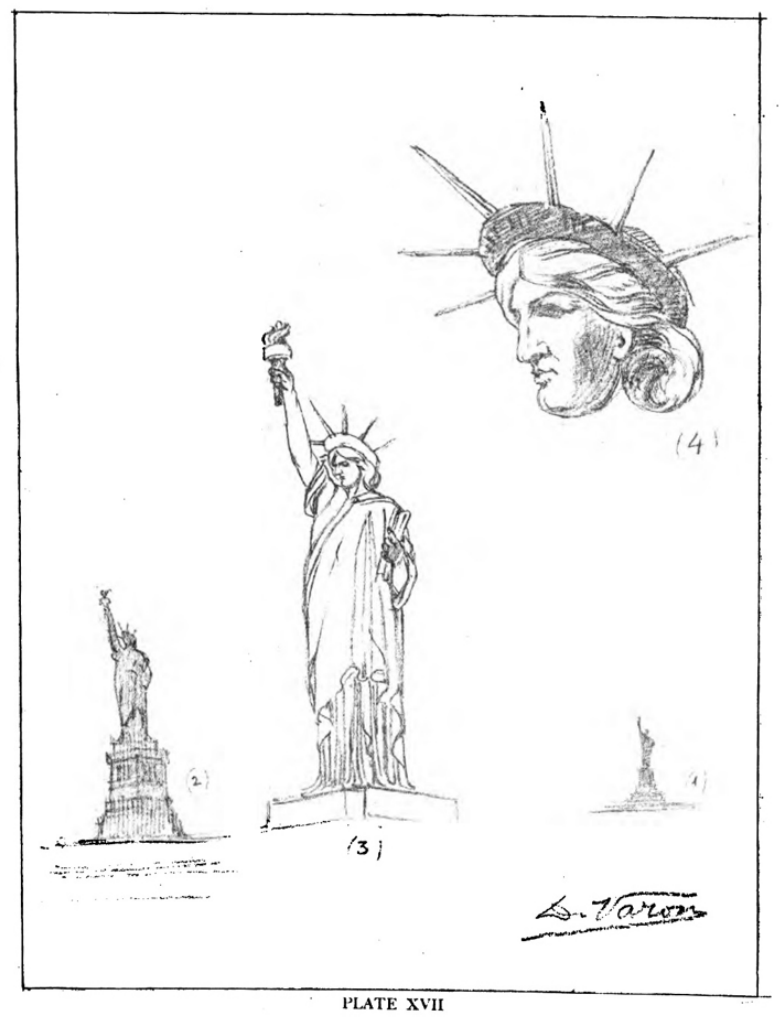

Fig. 53 The level of architectural detail visible from various distances. From Indication in Architectural Design by David Jacob Varon, 1916

lack of detail follows us as we move through many contemporary spaces.

This compositional impoverishment can have an unfortunately negative emotional impact upon those using these spaces.

By relearning lessons about the architectural design of buildings in the late $19^{\text {th }}$ and early $20^{\text {th }}$ Century, we can endeavor to do better.

\section{The Effect of Hand Drawing on the Character of Architectural Design of the Late $19^{\text {th }}$ and Early $2^{\text {th }}$ Century}

An additional interesting reason why contemporary architecture unfortunately often lacks hierarchically nested levels of detail lies with the physical media typically used in today's design process. Buildings today are usually designed with digital tools which, while quite powerful and useful in myriad ways, suffer a few distinct limitations. First, they often favor orthogonal shapes. Irregular and curved shapes - while possible to draw - generally require greater mental and physical effort, and are therefore disincentivized. Secondly, digital tools today also 


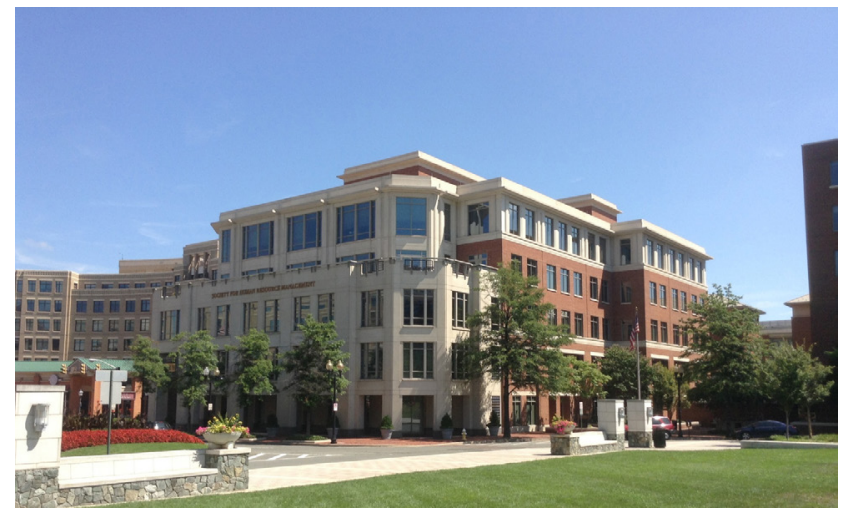

Fig. 55 A contemporary urban building in Alexandria, VA's Carlyle neighborhood, seen from a great distance. Photo: James Dougherty

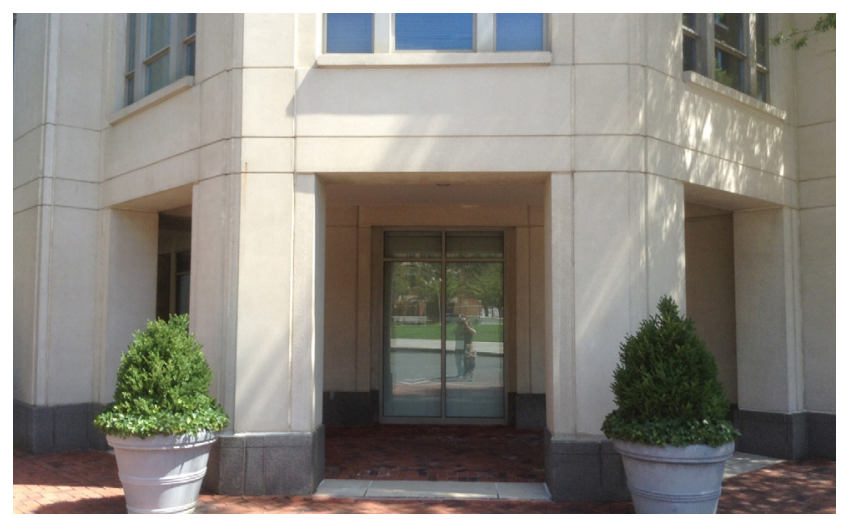

Fig. 57 From 6 meters. Photo: James Dougherty

facilitate easy repetition. It is usually much easier to copy a previously drawn window ad infinitum, for example, than to draw a new one with a different design.

These are areas where traditional hand drawing is an advantage. With hand drafting it is possible to produce orthogonal, irregular and curved lines all with similar ease and directness. It is also possible to easily alternate between drawing with instruments and freehand. Figurative sculpture with its curvilinear lines, for

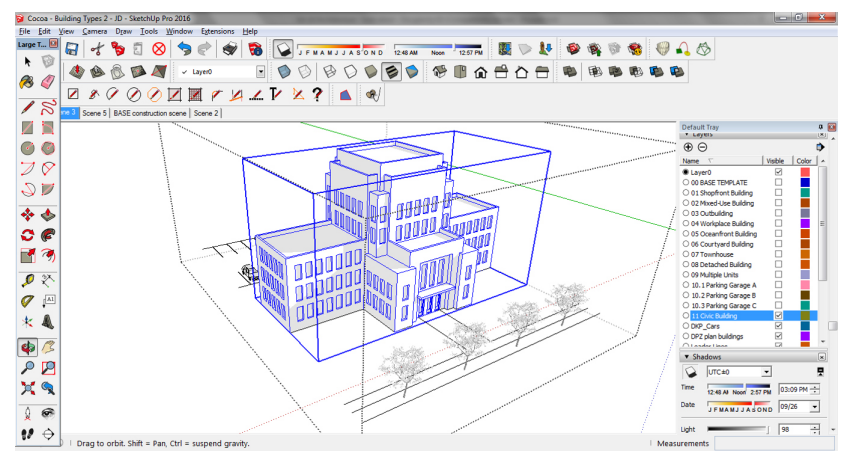

Fig. 59 Designing with today's digital modeling software. Photo: James Dougherty

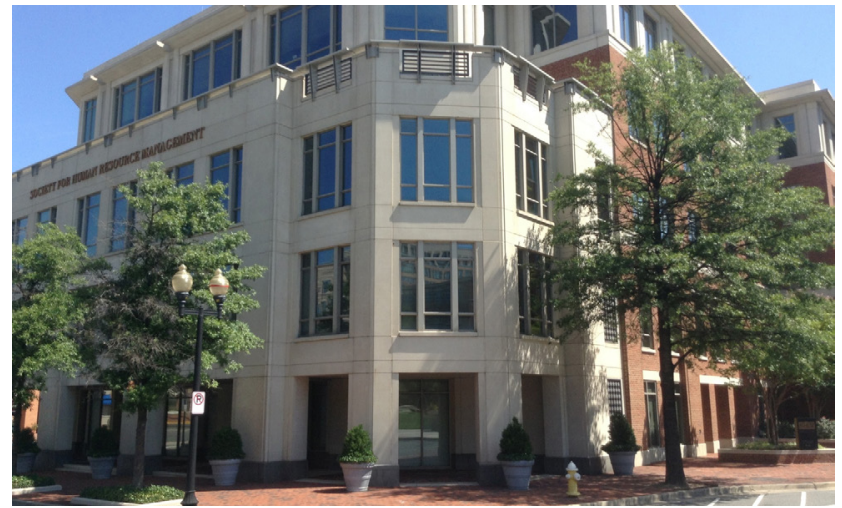

Fig. 56 Moving closer, the view from 30 meters. Photo: James Dougherty

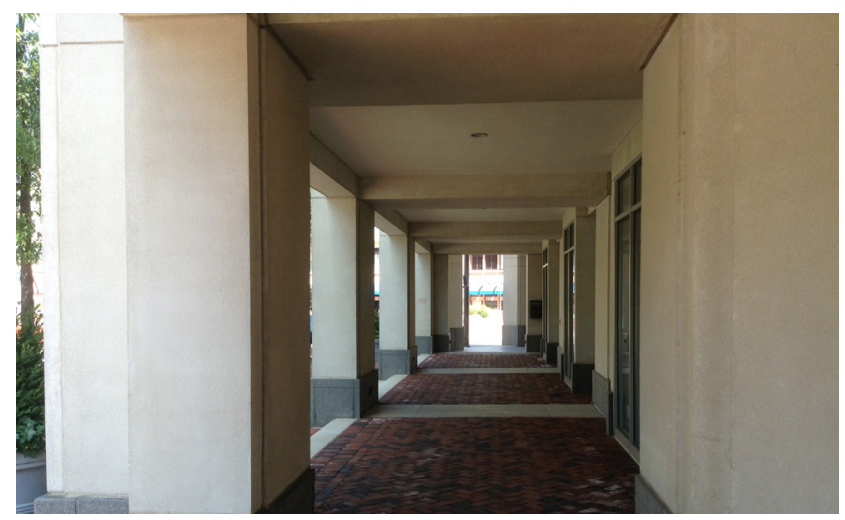

Fig. 58 Finally, standing on the sidewalk immediately in front of the building, one is confronted with an unfortunate expression of blankness. Photo: James Dougherty

example, is so dauntingly difficult to draw with many contemporary digital design platforms that it is hard to imagine including it in a contemporary design, but with hand drawing a figurative sculpture can be drawn quite quickly and efficiently.

There is also a natural incentive in hand drawing to avoid exaggerated, monotonous repetition because it is as tedious for the one drawing it as it will be for the one observing the built result.

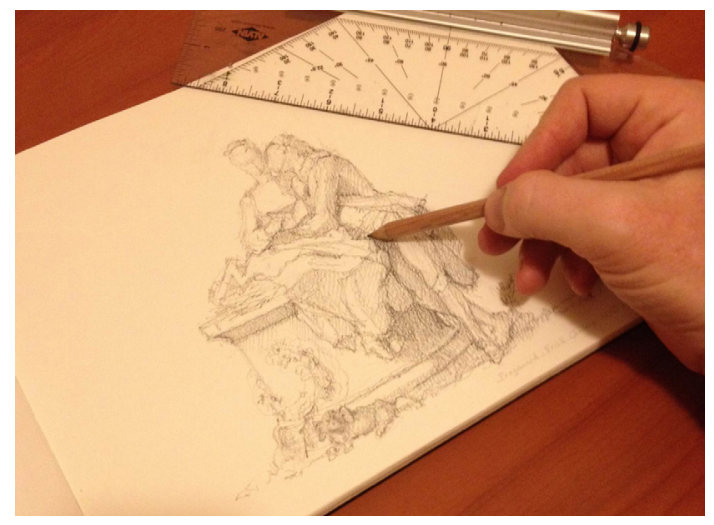

Fig. 60 Drawing with simple hand tools. Photo: James Dougherty 


\section{The Technique of "Indication"}

One of the largest advantages of hand drawing is its facilitation of the technique of "indication" as described by David Jacob Varon in his 1916 book of the same name. Indication is a technique of graphic shorthand where complex sculptural architectural forms are visually implied with a quick graphic shorthand (Varon, 1916:p.24).

When the technique of indication is employed by a skilled practitioner, a truly remarkable amount of architectural information can be conveyed by just a few quick marks and squiggles. The speed of this technique makes it possible to efficiently explore compositions as rich and complex as those of the late $19^{\text {th }}$ and early $20^{\text {th }}$ Century (Varon, 1916:p.24).

Varon has said of indication that "every touch of the pencil or pen has a meaning, and it is because of this expression to be found in every dot and dash, and also because of the numerous elements expressed by omission that sketching or indicating is so rapid" (Varon, 1916:p.24). And that "it offers the means of making several studies in one day, with excellent chances of expressing good ideas in each one, whereas without it he can barely make one study a day" (Varon, 1916:p.23).

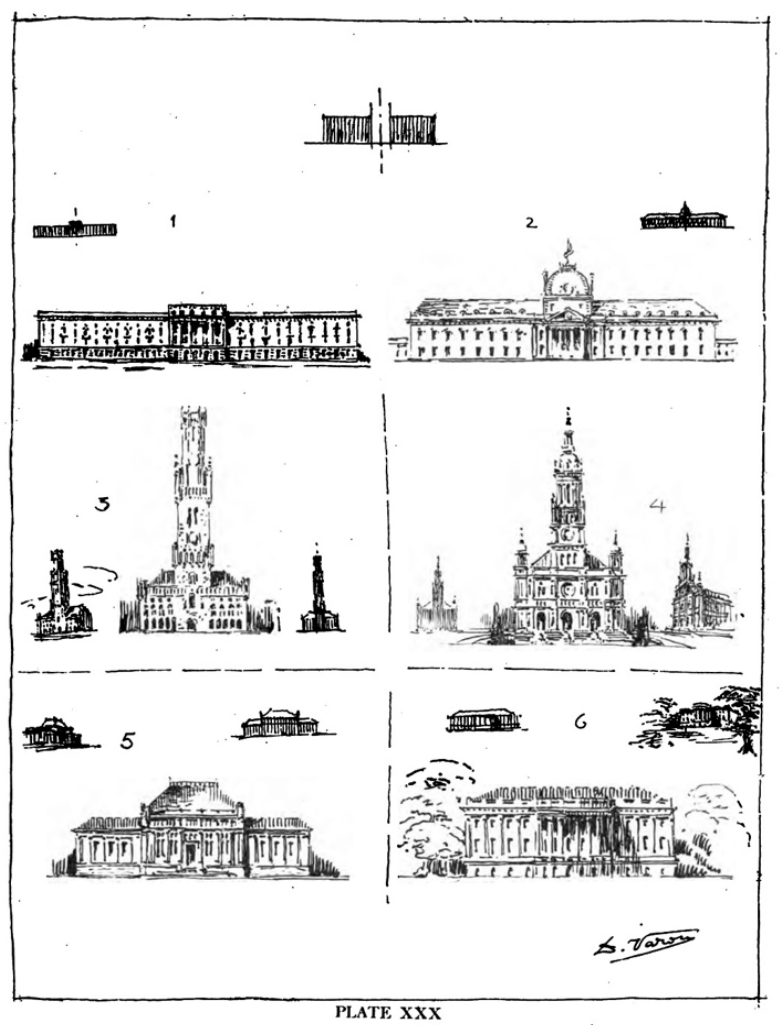

Fig. 61 Using quick indication to explore designs with a single primary mass. From Indication in Architectural Design by David Jacob Varon, 1916
When designing facades in the manner of the late $19^{\text {th }}$ and early $20^{\text {th }}$ Century, indication becomes more and more important as a designer progresses toward more detailed forms. The first large forms designed, such as overall massing and horizontal subdivisions, are often mostly rectilinear. The later, more detailed forms of sculptural embellishment are the most likely to employ curvilinear and non-orthogonal lines within their composition.

Take for example the exploration of a design for a door surround that is meant to incorporate a fair degree of ornament. With the digital 2D or 3D tools of today, it would be possible to draw a design for the large shapes but drawing the smaller elements of ornament quickly becomes almost absurdly difficult. Alternatively, with hand drawing by a practitioner skilled in the technique of indication, multiple design ideas for these figurative sculptures can be explored and drawn in a matter of minutes (Harbeson, 1927:pp.9-11).

It also bears mentioning that the relative ease of hand drawing makes architectural exploration of these details pleasurable to do. There is the reward of an enjoyable sense of free discovery for the designer engaging in this pursuit. This pleasure and high degree of reward for the designer makes it far more likely that they will readily

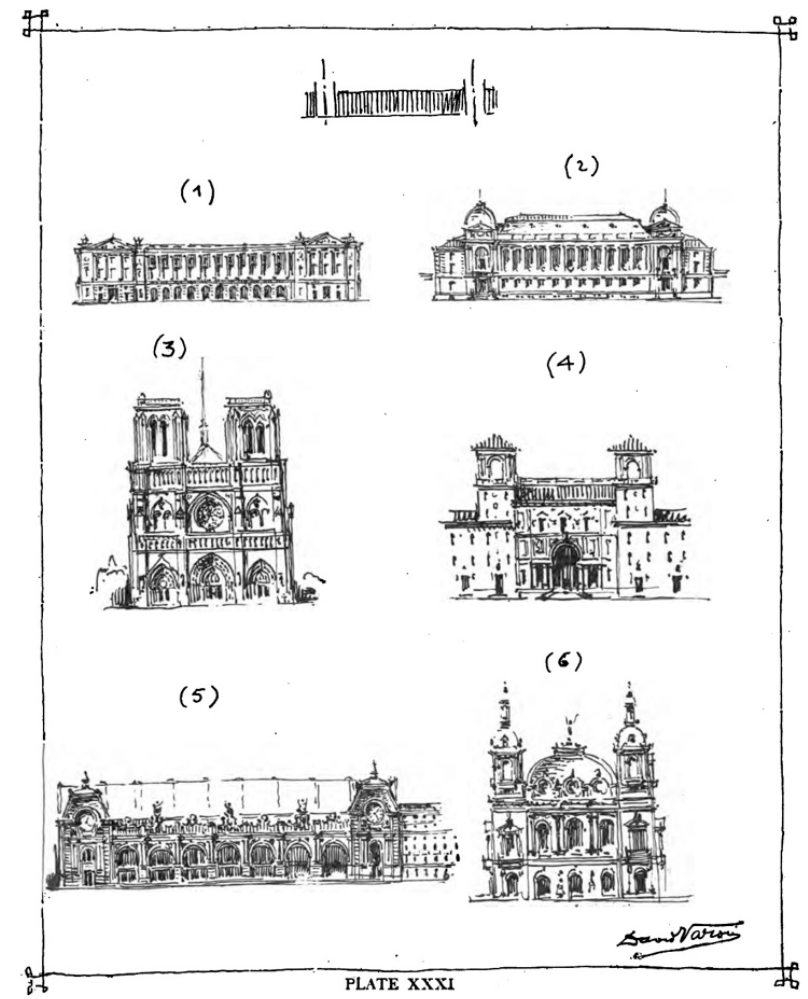

Fig. 62 Using quick indication to explore designs with two primary masses. From Indication in Architectural Design by David Jacob Varon, 1916 


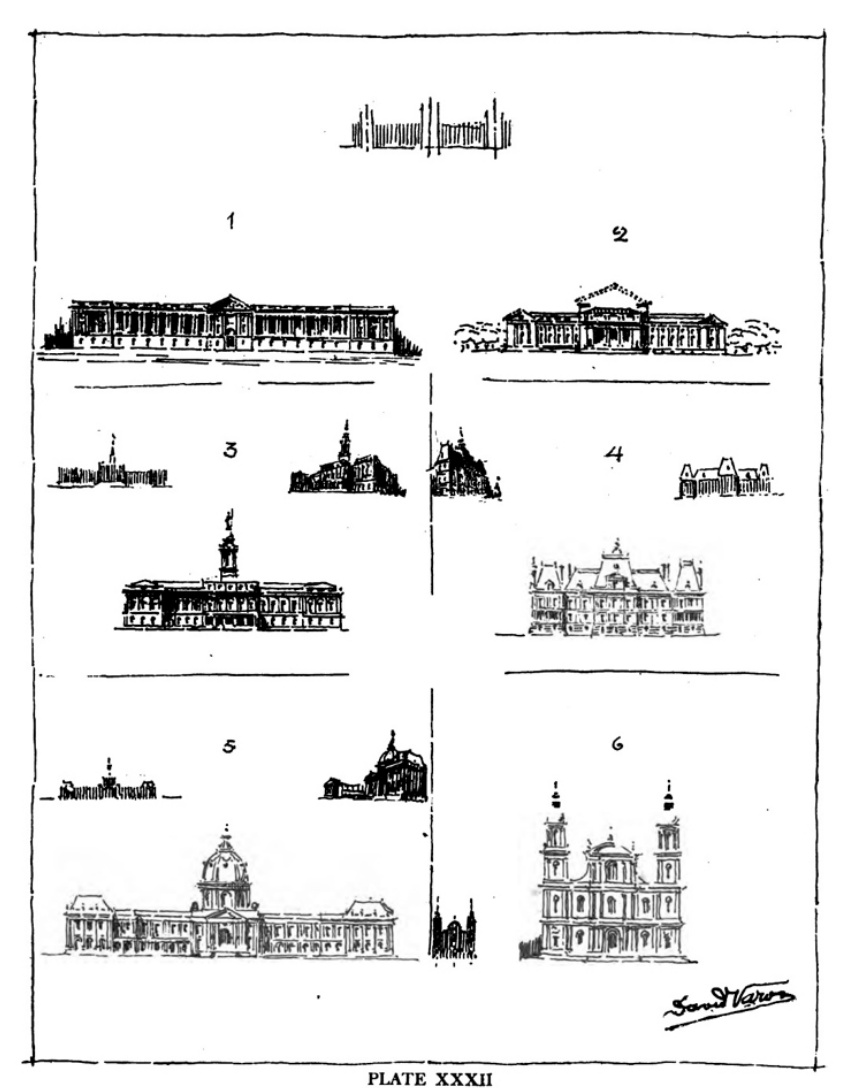

Fig. 63 Using quick indication to explore designs with three primary masses. From Indication in Architectural Design by David Jacob Varon, 1916

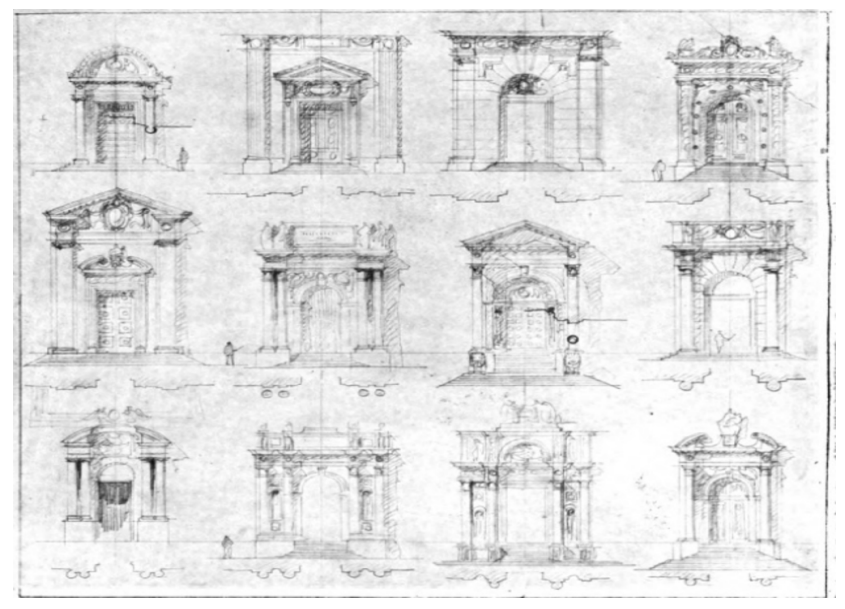

Fig. 64 Using indication to quickly explore design variations for a monumental doorway. From The Study of Architectural Design by John Harbeson, 1927

engage in the design of ornament and detail, and that these will find their way into architecture (Varon, 1916:p.44).

Therefore, to this day, hand-drawn indication remains one of the best tools available to facilitate the design of richly satisfying urban buildings with nested compositions

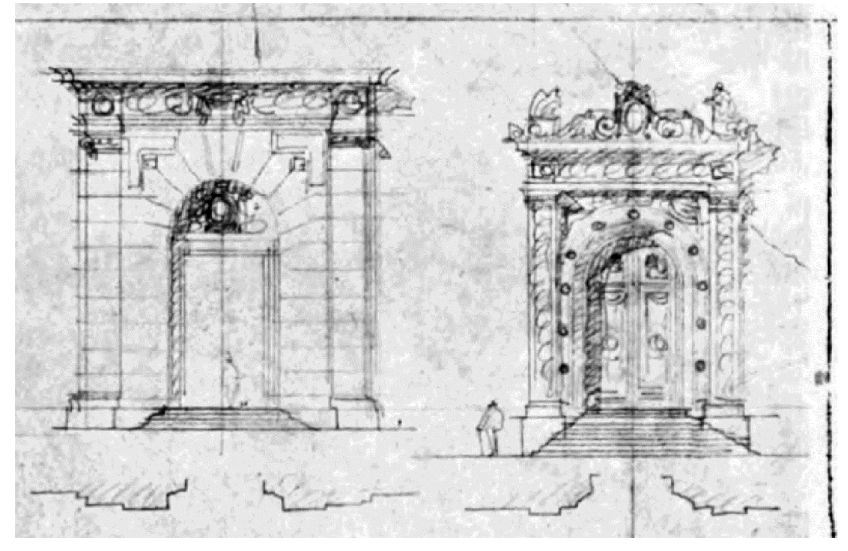

Fig. 65 Using indication to further refine design ideas for a monumental doorway. From The Study of Architectural Design by John Harbeson, 1927

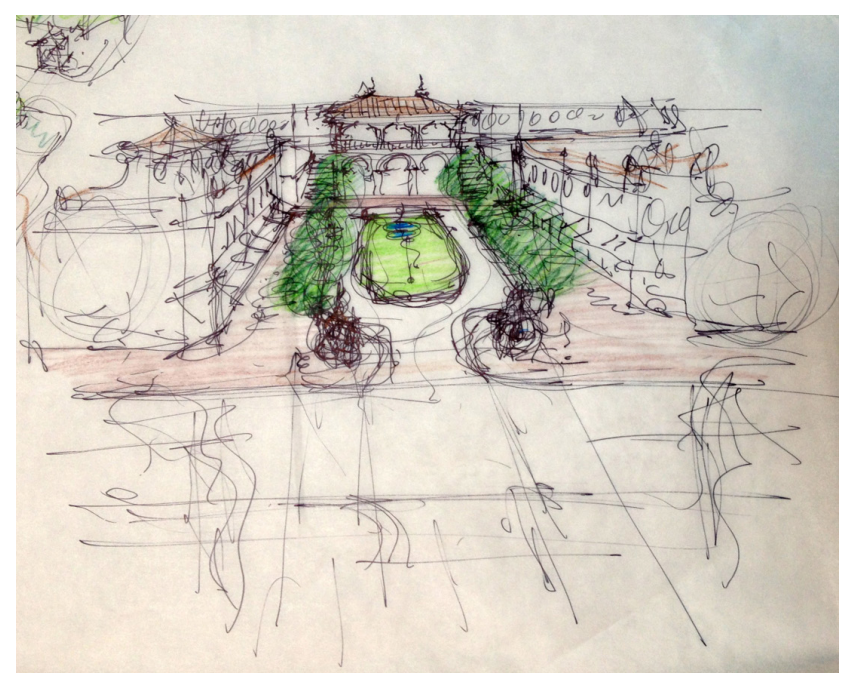

Fig. 66 Using indication in a contemporary design workflow. A new transit-oriented development for The Town of Babylon, NY. 2016. Image: James Dougherty - Dover, Kohl \& Partners

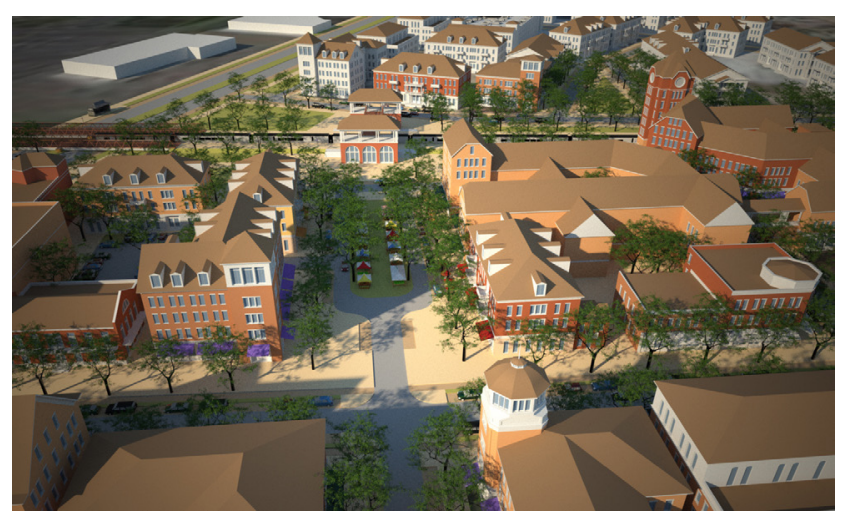

Fig. 67 Using digital modeling tools to further refine ideas begun with hand-drawn indication. A new transit-oriented development for The Town of Babylon, NY. 2016. Image: James Dougherty - Dover, Kohl \& Partners 
like those of the late $19^{\text {th }}$ and early $20^{\text {th }}$ Century and could be reincorporated into contemporary design workflows to powerfully complement digital drawing techniques.

\section{Looking Forward}

In conclusion, this has been a brief glimpse into the vast treasure trove of design principles and techniques employed by architects of the late $19^{\text {th }}$ and early $20^{\text {th }}$ Century.

My sincere hope is that by exploring and sensitively reintegrating these methods into today's design processes, we can advance the positive evolution of built results to achieve new urban environments that are as legible, harmonious and satisfying for today's people to inhabit as any in history.

\section{References}

Curtis, N. C. (1923) "Architectural Composition", J. H. Jansen, Cleveland, Ohio, USA.

Harbeson, J. F. (1927) "The Study of Architectural Design", Pencil Points Press, New York, USA.

Loomis, A. (1947) "Creative Illustration", The Viking Press, New York, USA.

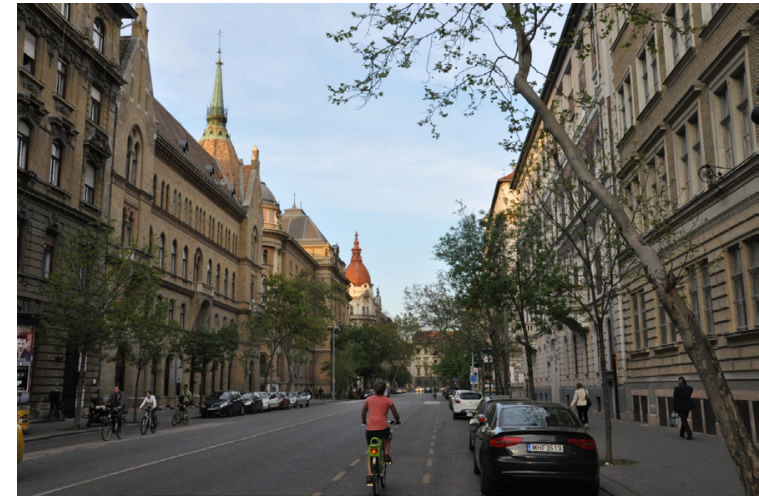

Fig. 68 Using revived late $19^{\text {th }}$ and early $20^{\text {th }}$ Century design techniques, the composition of new urban environments as harmonious and satisfying as Budapest's Alkotmány utca can be achieved today. Photo: James Dougherty

Robinson, J. B. (1908) "Architectural Composition", D. Van Nostrand Company, New York, USA.

Varon, D. J. (1916) "Indication in Architectural Design", The William T Comstock Company, New York, USA. 